\title{
Ultimate loads and response analysis of a monopile supported offshore wind turbine using fully coupled simulation
}

\author{
A. Morató \& S. Sriramula \\ LRF Centre for Safety and Reliability Engineering, Aberdeen, United Kingdom \\ N. Krishnan \\ Lloyd's Register EMEA, Aberdeen, United Kingdom \\ J. Nichols \\ Lloyd's Register, London, United Kingdom \\ *Corresponding author: Srinivas Sriramula \\ Lloyd's Register Foundation (LRF) Centre for Safety \& Reliability Engineering, \\ School of Engineering, University of Aberdeen \\ Aberdeen, AB24 3UE, UK. \\ Phone: +44 (0)1224 272778, Fax: +44 (0) 1224-272497 \\ Email: s.sriramula@abdn.ac.uk
}

1

ABSTRACT

The current design of offshore wind turbines follows mainly the IEC 61400-3 standard. The list of Design Load Cases (DLCs) implied for this standard is comprehensive and the resulting number of time domain simulations is computationally prohibitive. The aim of this paper is to systematically analyse a subset of ultimate limit state load cases proposed by the IEC 61400-3, and understand the relative severity among the load cases to identify the most critical among them. For this study, attention is focused on power production and parked load cases. The analysis is based on the NREL 5 MW prototype turbine model, mounted on a monopile with a rigid foundation. The mudline overturning moment, as well as the blade-root in-plane and outof-plane moments are taken as metrics to compare among the load cases. The simulations are carried out using the aero-hydro-servo-elastic simulator, FAST, and the key observations are thoroughly discussed. The DLC $1.6 \mathrm{a}$ is shown to be the most onerous load case. Although the considered load cases are limited to power production and idling regimes, the obtained results will be extremely useful for the substructure (monopile) design and for efficient reliability analysis subsequently, as is also shown partially by some previous studies.

Keywords:

Offshore wind turbine; Design load case; Monopile; Response analysis; Support structure; Ultimate load

\section{INTRODUCTION}

Depleting fossil fuel reserves and ever-increasing demand for energy have resulted in rapid development of renewable energy sources. Offshore wind energy presents huge potential in this regard. The combination of the hydrodynamic loading from waves and current, the aerodynamic effects of wind, structural dynamics of the support structure, and the nonlinear effects of the controller together make the design of Offshore Wind turbines a very challenging exercise. From a structural design perspective, several factors have to be considered in the 
design of Offshore Wind Turbine (OWT) support structures, which are absent in their onshore counterparts.

The current design of OWT support structures is performed largely following the IEC 61400-3 standard [1], which proposes a number of design situations representing the various modes of operation of the turbine, with each design situation leading to a number of Design Load Cases (DLCs). The IEC standard distinguishes two types of load cases, namely ultimate and fatigue load cases, with a further subdivision of Ultimate Limit State (ULS) cases as Normal, Abnormal and Transportation cases. The design standard recommends appropriate load factors to be associated with these load cases and also offers guidance on methods of evaluating the DLCs in order to check the structural integrity of the offshore wind turbine. The background work that forms the basis of the DLCs is proposed in $[1,2]$ and is summarized in technical reports [3].

The DLCs listed in the IEC standard are comprehensive and require thousands of time domain simulations. There have been efforts to study various DLCs in detail. RECOFF [3] was the first project that addressed the complexity of the combination of the Oil\&Gas offshore standards and the existing onshore wind energy standards, proposing a series of recommendations for the design of OWT [4], it also led to the elaboration of the IEC 61400-3 [1]. Other authors such as Tarp-Johansen applied the design standards to the design of OWT in the US and also studied the partial safety factors and characteristic values for extreme load effects $[5,6]$. More recently NREL did a lot of work related to floating OWTs, studying the influence of the simulation length of the DLC on the uncertainties in ultimate and fatigue loads [7] and structural response of different OWT concepts, while also comparing the results with the onshore structures. Agarwal $[8,9]$ studied the DLC 1.2 (normal operation in turbulent wind and stochastic waves) in detail and the implications of nonlinear wave loading on the load extrapolation procedure. Moriarty et al [10] studied the DLC 1.1/1.2 and outlined a method of statistical extrapolation procedure. Cheng [11] performed a thorough analysis on the effect of the number of wind and wave seeds and simulation length on the maximum response distribution and concluded that 50 simulations of $40 \mathrm{mins}$ can be considered sufficient for studying the chosen responses.

A number of relevant DLCs proposed by the IEC standard were studied in the UPWind project $[12,13]$. In the preliminary design phase of UpWind 4.2.5 [12] the wind loads were studied through the fatigue DLCs 1.2 and 6.4 and the extreme cases 1.3, 1.4, and 6.2a in a calm sea for a jacket substructure. For the final design phase, the considered DLCs were 2.2 and 2.3 which include system faults, and 1.6a, 6.1a and 6.2a. However, these studies were based on the assumptions such as 1-min turbulent wind and a positive small yaw misalignment. The fault cases were found not to be influencing the support structure, whereas DLC 6.1 showed the severest load condition. In addition, UpWind 4.2.8 [13] considered a reference support structure for monopile and jacket and applied a subset of DLCs on these structures. This work considered the fault load cases among other ULS load cases. The results of the ULS checks for the substructure (yield and buckling) showed that DLCs 6.1a and 6.2a appear to be governing for the monopile, whereas fault DLCs were again not influencing the loading at the seabed level. The fault cases were found to be relevant to the tower. It is to be noted that, in these studies [12, 13] the DLCs were not studied in detail to understand the causes of the maximum values and the parameters affecting them, only the results at different locations of the structure were shown. 
Kim et al. [14] focused on identifying the effect of the substructure type on the load characteristics of the superstructure such as the blade, hub or tower under ULS DLCs 1.6a, 6.1a and 6.2a and fault DLCs 2.1 and 2.2. The latter were not found to be design driving in any case for the monopile. It is to be noted that the focus on substructure was limited in this study, as the emphasis was more on blades and tower-top interface. Cordle et al. [15] studied the design drivers for OWTs using jacket support structures and investigated the fatigue DLCs 1.2 and 6.4, in addition to a previously considered set of extreme DLCs. It was observed that the severest extreme loading combination was given by DLC 6.1a. A clear understanding of the significance of parameters affecting the extreme values of different DLCs provides an opportunity to study the reliability of OWT substructures efficiently [16]. More recently, Galinosa et al. [17] presented a detailed load case analysis for onshore Vertical Axis Wind Turbines (VAWT) and compared with corresponding loads for Horizontal Axis Wind Turbines (HAWT). However, as the focus was on onshore turbines, it is not directly relevant for the present work.

To conclude, despite the extensive literature sampled above, to the authors' knowledge, there exists no work that systematically compares all the potentially relevant design load cases for substructure design, and ranks them in order to offer useful starting points for designers and researchers. This work aims to fulfil this gap by developing a comprehensive analysis of the most relevant Ultimate Limit State DLCs that a designer has to go through to assure that the OWT will perform satisfactorily for the entire design life. The DLCs studied are taken from the IEC 61400-3 [1] standard. The focus is on power production and parked/idling load case subset, specifically on DLCs 1.1,1.3, 1.4, 1.5, 1.6a, 6.1a and 6.2a. The cases considered in this study were limited to those driving the design loads for the pile and being dominated by wave and wind loading during normal operation. This choice is partially justified based on the results of previous literature and industrial experience. Fault cases were not considered as they are more sensitive to the details of the wind turbine supervisory control and it was considered that this would produce less universally applicable conclusions. The loads arising from start-up and shut-down cases are quite specific to the controller adopted, and hence those load cases are not chosen for our study (see also [17]).

This study compares the key parameters for the design of both the rotor/nacelle assembly and the support structure such as: flapwise (out-of-plane) and edgewise (in-plane) moment at the root of the blade and the overturning moment at the seabed (mudline moment). The simulations are carried out using FAST 8 [18], an aero-hydro-servo-elastic simulator developed by the National Renewable Energy Laboratory (NREL). The turbulent wind is generated by TurbSim [19] and coupled with FAST. All the DLCs are applied to a benchmark which corresponds to the monopile structure model of the phase I of the Offshore Code Comparison Collaboration (OC3) [20]. It is to be noted that the present study is limited to a prototype wind turbine structure with a rigid foundation. The metocean data used is site-specific and the attention is restricted to the power production and parked load cases.

\section{BENCHMARK AND METOCEAN DATA}

\subsection{Benchmark}

The structure used for the study is the 5MW monopile OWT model from the OC3 project [20]. The main characteristics are described in Table 1 . The platform has a constant thickness of $0.06 \mathrm{~m}$ with a diameter of $6 \mathrm{~m}$ whereas the tower diameter and thickness decrease linearly, the 
diameter from 6 to $3.87 \mathrm{~m}$ and thickness from 0.027 to $0.019 \mathrm{~m}$, further information can be found in [21].

\subsection{Metocean data}

The location chosen for this study is based on the Ijmuiden Shallow Water Site from the Upwind design basis [22]. The site is found in the Dutch North Sea, the coordinates of Ijmuiden site are $52^{\circ} 33^{\prime} 00^{\prime \prime}$ east and 403'30" north. The metocean data is presented as 3-hour average values for a period of 22 years. This location has been chosen in order to work with a realistic, consistent and reasonable metocean dataset as the corresponding water depth and hub height of this site matches well with the chosen benchmark monopile and water depth.

The main variables used in the following sections are shown next. The water levels used are the Highest Still Water Level (HSWL) and Highest Astronautical Tide (HAT) which are 2.4 and $1.4 \mathrm{~m}$ above the Mean Sea Level (MSL). For normal current loads an average value of $0.6 \mathrm{~m} / \mathrm{s}$ at surface level is taken and for the extreme case a value of $1.2 \mathrm{~m} / \mathrm{s}$ is considered.

The values for the extreme wave conditions were found to follow Equation (1) resulting in the extreme wave height values shown in Table 2 [22]. A factor of 1.86 can be used to obtain the maximum wave height in equation (2) as the water depth is relatively shallow [1].

$$
\begin{gathered}
H_{S, 3 h}\left(T_{\text {return }}\right)=0.479 \cdot \ln \left(T_{\text {return }}\right)+6.0626 \\
H_{\max }=1.86 \cdot H_{S, 3 h}
\end{gathered}
$$

where $H_{S, 3 h}$ is the significant wave height for a 3-hour reference period, $T_{\text {return }}$ is the return period corresponding to $H_{S, 3 h}$ and, $H_{\max }$ is the Extreme Wave Height (EWH).

Moreover, the extreme wind values are determined from the measured data using a 10 minute reference period. The measured data is fitted to a Weibull distribution with parameters $A=$ $10.61 \mathrm{~m} / \mathrm{s}$ and $k=2.08$. The extreme wind speed is defined as the maximum wind speed that occurs with a certain return period, resulting in Equation (3). The common return periods used for the wind speed and their results can be seen in Table 2 [22].

$$
V_{\text {hub }, 10 \min }\left(T_{\text {return }}\right)=2.6446 \cdot \ln \left(T_{\text {return }}\right)+31.695
$$

where $V_{h u b, 10 \min }(x)$ is the wind speed at the hub.

Power production DLCs, among others, use the significant wave height conditioned on wind speed. Table 3 shows eleven wind speed bins of $2 \mathrm{~m} / \mathrm{s}$ size, from the cut-in to cut-out wind speeds. The table also lists the significant wave height and peak spectral periods associated with the wind speed [22].

\subsection{Modeling assumptions}

For this study many simulations need to be performed to cover all the studied DLCs and thus some assumptions and simplifications need to be applied to facilitate and optimise the procedure. These are given in the following paragraphs:

- Writing and reading the turbulent wind field created by TurbSim [19] is very timeconsuming, therefore the grid size is set to $13 \times 13$ points comprising an area of $155 \times 155 \mathrm{~m}^{2}$. 
- The wind turbine uses a conventional variable-speed, blade-pitch-to-feather configuration. The method for controlling power-production operation relies on the design of two primary control loops: a generator-torque controller and a full-span rotorcollective blade-pitch controller. The goal of the generator-torque controller is to maximize power capture below the rated operation point. On the other hand, bladepitch controller aims to regulate the generator speed above the rated operation point. NREL developed the NREL offshore 5-MW wind turbine's baseline control system as an external Dynamic Link Library (DLL) which is called by ServoDyn. Further information about this routine can be found in [21].

- It is also assumed that the wind turbine is class II within the framework found in IEC [2] as it fits with wind data. The turbulence reference intensity is chosen as B (0.14) as class $A$ is unlikely to be found offshore, unless the spacing within the wind farm is lower than typically found, and hence quite conservative.

- HydroDyn uses Morison's equation to model the hydrodynamic loading; it uses Airy's theory to define the inertia and drag loading, both containing two empirical hydrodynamic coefficients-an inertia coefficient and a drag coefficient.

- The current is modeled as a near-surface current, the model follows a linear relationship down to a reference depth, further information can be found in the FAST user guide [18].

- The time span for each simulation is increased by 30 seconds, and the simulation results for the initial 30 seconds were ignored to discount the start-up transients.

- For the DLCs which include deterministic wind transient changes spanning 10-12 seconds, the initial results spanning 30 seconds are deleted. Also, the start time for the event is set at 80 seconds and the simulation time span is fixed as 120 seconds. This combination gives enough time to analyse the DLC before and after the transient phase dies out.

\section{DESIGN LOAD CASES}

This section goes through the subset of the IEC [1] DLCs considered in our study. As mentioned earlier, attention is hereby restricted to the power production and parked load cases. More specifically, the load cases considered are; 1.1, 1.3, 1.4, 1.5, 1.6a, 6.1a and 6.2a. A brief summary of these DLCs is given in Table 4.

Each DLC is analysed separately highlighting the main characteristics of the environmentstructure interaction. Three response variables are chosen as metrics for comparison among the DLCs; the flapwise (out-of-plane) moment and edgewise (in-plane) moment at the root of the blade and the overturning moment at the seabed. The first two are widely used for the design of blades whereas the third drives the support structure design. The flapwise moment is the cause of the out-of-plane blade tip deflection whereas edgewise moment creates an in-plane blade tip deflection. Considering the directional nature of loading, Equation (4) defines the overturning moment at the mudline following the coordinate system shown in Figure 1.

$$
M_{\text {Overturning }}=\sqrt{M_{x}^{2}+M_{y}^{2}}
$$

\subsection{Power production DLCs}

This design situation simulates an OWT which is running and connected to the grid and hence the turbine is producing electricity within the cut-in and cut-out range of wind speed. The DLCs 
simulated corresponding to this design situation are 1.1, 1.3, 1.4, 1.5 and 1.6a. DLC 1.6b is not included in current common practices for being not design driving and therefore it is omitted in this section.

In these conditions the turbine is considered to use a torque and pitch controller implemented in GH Bladed-style DLL format. The DLL (i.e., DISCON.dll) is supplied with the NREL 5-MW models [21]. Pitch control will twist the blades by linking the angle of attack to wind speed fluctuation whereas the variable-speed torque controller controls the rotor speed in order to capture as much power as possible when the wind speed is below rated. This turbine does not use a yaw controller; to account for the lack of it, some DLCs are simulated in this paper with small yaw misalignments representing the possible yaw control delay. For heavily-loaded rotors (i.e. at low wind speeds) the Generalized-Dynamic Wake (GDW) option (DYNIN) of AeroDyn is numerically unstable [23] and hence the EQUIL model is set in AeroDyn instead of DYNIN for all the simulations within the power production DLCs.

\subsubsection{DLC 1.1}

As the OWT does not include a yaw controller, the simulations are also performed with a yaw misalignment of $0^{\circ}$ and $\pm 8^{\circ}$ in order to account for the small delay that a yaw controller could have. The IEC standard states that the number of simulations carried out for each mean wind speed and sea state combination shall be sufficient to determine a reliable long term probability distribution of extreme values for extrapolation to the characteristic load effect. The present study considers six 10-minute simulations which result in a total of 198 simulations if seeds, wind bins and yaw misalignment are taken into account ( 6 seeds $\mathrm{x} 11$ wind speed bins $\mathrm{x} 3$ yaw angles). The purpose of this DLC is not to provide instantaneous histories for loads at desired sections, but to statistically extrapolate the load response results of all multiple stochastic simulations in order to achieve the structural response for a 50 year return period.

To do that, all the simulations corresponding to all the wind speed bins and yaw misalignment angles are performed. For each wind bin, the mean of the 6 maximums ( 6 seeds) of the overturning moment is taken, in this case corresponding to a yaw misalignment of $0^{\circ}$. Then all the values of the time-series are sorted from smallest to largest and the Cumulative Distribution Function (CDF) is obtained. After that a Gumbel distribution is fitted to the CDF by minimising the least squares error corresponding to the distribution parameters. In order to not overestimate the tail of the distribution a method which weights the error by the load prediction difference between the two points is used. Therefore, in the tail region, where there are fewer points, each point has relatively more importance. The result can be seen for the overturning moment at the seabed in Figure 2, the same procedure is applied for the flapwise and edgewise moments at the root of the blade.

The probability of exceedance related to a 50 year event is taken as $3.8 \mathrm{E}-07$ [1] and it is found using Equation (5), where $N$ corresponds to the total number of independent 10-minute intervals in 50 years.

$$
P_{\text {Exceedance }}=1 / N
$$

228 A load factor of 1.25 is applied to the results after the extrapolation. These extrapolated values 229 are used to calibrate DLC 1.3, the extreme values derived from DLC 1.3 need to be equal or 230 higher than the extrapolated ones assuring this way that the structural response is related to a 23150 year event. If the results from DLC 1.3 turn out to be lower than the extrapolated value from 
DLC 1.1, then the Extreme Turbulence Model (ETM) in DLC 1.3 is re-calibrated by increasing the $c$ value, until the results from DLC 1.3 approach or exceed the extreme load computed in DLC 1.1.

\subsubsection{DLC 1.3}

This power production DLC has the same features as DLC 1.1 except for the wind model; DLC 1.3 uses the ETM instead of the Normal Turbulence Model (NTM). It is also simulated with a slight misalignment to account for the lack of a yaw controller. The length and number of simulations are the same as in DLC 1.1 (198), although there is no requirement to perform extrapolation in this case. The wind, wave and current loading corresponding to the DLC are applied to the model, and Figure 3 shows how the maximum values of each seed of the overturning moment and rotor thrust evolve over the wind speed bins, for the case corresponding to a yaw misalignment of $-8^{\circ}$.

As the rotor thrust is measured along the shaft and it rotates with the nacelle-yaw angle, it would be expected that thrust and tower-top loads should be very similar between onshore and offshore monopile configurations. Generally, in pitch controlled OWT, higher loads are achieved when wind speed is around rated wind speed, although a small yaw misalignment deforms the trend at higher wind bins giving higher maximums for 20 and $22 \mathrm{~m} / \mathrm{s}$, for a $-8^{\circ}$ and $8^{\circ}$ yaw misalignment, respectively. Furthermore, the characteristic load, the highest mean value of the overturning moment maxima (dashed line in Figure 3), derived from this DLC is 1,167E+08Nm for a mean wind speed of $16 \mathrm{~m} / \mathrm{s}$ and a yaw misalignment of $0^{\circ}$.

Two seeds are further investigated in Figure 4 to analyse the variability observed for wind speed bins of $18 \mathrm{~m} / \mathrm{s}$ and $22 \mathrm{~m} / \mathrm{s}$. The overturning moment maxima occur at different times, but the cause seems to be the same; a decrease and increase of the wind speed causing a trough in the pitch angle. This rotation towards $0^{\circ}$ of the blade pitch angle creates a significant resistance to the wind force and hence a peak in the overturning moment, the closer to $0^{\circ}$ the trough gets, the higher the overturning moment becomes. Figure 5 helps in order to study this phenomena further, it shows the pitch angle and the wind speed when the overturning moment maxima occurs. The mean of the 6 seeds shows a rising trend over the wind bins, but interestingly, higher pitch angle and wind speeds when maxima occurs mean lower overturning moments. To summarise, it can be seen that the fluctuation of the wind speed causes pitch angle troughs, if this happens close to the rated wind speed a higher overturning moment is to be expected. In addition, larger fluctuations (turbulence) increase the chances of the wind speed decreasing close to rated wind speed, creating deeper pitch angle troughs, and therefore higher overturning moments. This also explains that, since we are using the ETM, the location of the peak area in Figure 3 falls in the range of $14-18 \mathrm{~m} / \mathrm{s}$, whereas if the same graph was plotted using NTM, the peak would correspond to a lower range of wind speed bins, $12-14 \mathrm{~m} / \mathrm{s}$, and the tail would go lower. The short-term wave height seems not to have a significant influence on the timing of the maximum loads. In Figure 4, the edgewise moment fluctuates with the wind speed, but as there is no wind direction change this parameter is not that affected. On the other hand, the flapwise moment at the root of the blade is more dependent on the wind oscillation and it is also greatly affected by the pitch angle actuator delay, therefore both maxima come when pitch angle approaches $0^{\circ}$, the same situation as for the maximum overturning moment.

As explained in the case of DLC 1.1, the design load from DLC 1.3 needs to be equal to or exceed the extrapolated values from DLC 1.1. It is seen from Table 5 that only the design overturning 
moment exceeds the results from DLC 1.1, for the purposes of this study, these small differences are acceptable and therefore simulations are not performed again by increasing the value $c$.

\subsubsection{DLC 1.4}

This DLC might be quite sensitive to the initial azimuth angle of the blades, therefore it is studied for 4 different initial azimuth angles of blade $1: 0^{\circ}, 30^{\circ}, 60^{\circ}$ and $90^{\circ}$, and for the same reason as for previous DLCs the simulations are also carried out for a yaw misalignment of $0^{\circ}$ and $\pm 8^{\circ}$. Although a stochastic Normal Sea State (NSS) with a significant wave height conditioned on rated wind speed is used, no seeds are used for this DLC, leading to a total of 72 simulations ( 6 wind types ( $\mathrm{ECD} \pm \mathrm{r} \pm 2$ ) $\mathrm{x} 4$ azimuth angles $\times 3$ yaw angles).

This DLC consists of an increase in the magnitude of wind speed, along with a wind direction change of approximately $60^{\circ}$, which results in a small increase of the $V_{x}$ while $V_{y}$ increases from 0 . At the same time the blade pitch angle tries to adapt to the variation of $V_{x}$. As the wind angle increases, $V_{x}$ decreases again approaching its original value. This is shown clearly in Figure 6 for the case of Extreme Coherent gust with Direction change at a rated wind speed (ECD-r) with $8^{\circ}$ of yaw misalignment and as an initial azimuth angle of $30^{\circ}$.

This DLC is analysed in a different way compared to the previous ones; in this case, neither seeds nor wind bins are accounted. However, it is of interest to observe the correlation between the initial azimuth angle of blade 1, the small yaw misalignment and the maximum overturning moment. To do that, the overturning moment is plotted as a function of yaw and azimuth angle as shown in Figure 7. The aim of this 3D plot is not to extract the exact values, but to understand if either yaw or initial azimuth angle influence the overturning moment. An overall view of Figure 7 shows the negligible influence of azimuth angle except for the case of ECD $\pm r$ where a small variation can be observed. On the other hand, there seems to be a global correlation between the direction of the wind rotation and the yaw misalignment although the change of the wind direction at around $60^{\circ}$ has a much higher effect than yaw misalignment. The coordinate system of FAST in representing wind, wave and yaw angles is shown in Figure 8.

The maximum overturning moment of this DLC is $1,217 \mathrm{e}+08 \mathrm{Nm}$ and it is observed for a wind ECD-r with $a+8^{\circ}$ yaw misalignment and $30^{\circ}$ initial azimuth angle of blade 1 . In Figure 7 the correlation between the overturning moment and yaw angle shows that below rated, the load is higher when the total yaw angle is higher. However, for wind speeds above rated, the overturning moment is higher when the wind direction change opposes the original yaw misalignment.

The same analysis is carried out with respect to the flapwise and edgewise moments at the root of the blades. These two parameters are more directly influenced by the wind than the overturning moment. The initial azimuth angle of blade 1 does not influence the flapwise moment magnitude, although the yaw angle does have an effect, especially in cases where the wind speed is $2 \mathrm{~m} / \mathrm{s}$ above rated. When the rotation of wind speed is negative higher moments are observed with negative yaw angles and the opposite happens when the rotation is positive. Also, in contrast to the overturning moment, with the flapwise moment there is a clear correlation with the wind speed, higher winds leading to higher moments. Overall it is concluded that the higher the yaw misalignment the higher the flapwise moment will be and the magnitude will depend on the wind speed. On the other hand, the edgewise moment gives higher values for anticlockwise wind rotations and higher wind speeds. There is also a slight 
correlation with the yaw angle and for some of the wind types, there seems to be a random correlation with the initial azimuth angle of blade 1, probably because it depends on the phase of the blade position with the timing of the gust. The severe conditions stated above are shown in Figure 9.

The simulation denoted by ECD $\pm r$ with the highest overturning moment corresponding to $+8^{\circ}$ yaw misalignment and $30^{\circ}$ of initial azimuth angle is analysed in detail. As shown in Figure 10 the wind direction change implies a sharp drop in the value $\mathrm{M}_{\mathrm{xy}}$ when the wind stops facing the rotor, although it reaches a maximum value at $83.75 \mathrm{~s}$ right after the gust starts due to the small peak in $V_{x}$ seen in Figure 6. Since there is a wind direction change, the drop of $M_{x y}$ is due to the sharp decrease of $M_{y}$ as shown in Figure 11, whereas $M_{x}$ barely changes in magnitude.

This DLC is clearly dominated by the wind gust and direction change, the influence of waves is hence secondary. Figure 12 shows how the negative angle of wind direction change causes situations with higher overturning and edgewise moments. It is also observed that the flapwise moment is instead dominated by wind speed magnitude.

\subsubsection{DLC 1.5}

This DLC is also carried out with different initial rotor azimuth angles: $0^{\circ}, 30^{\circ}, 60^{\circ}$ and $90^{\circ}$; as well as a yaw misalignment of $0^{\circ}$ and $\pm 8^{\circ}$. The transient start is at 80 seconds and each simulation lasts for 120 seconds. No seeds are used even though a stochastic NSS is used together with $H_{S}=E\left[H_{S} \mid V\right]$ [1]. The final number of simulations is observed to be 528 (11 wind bins $\times 4$ wind types (EWSH $\pm v$ and EWSV $\pm v$ ) $\times 4$ azimuth angles $\times 3$ yaw angles).

The relation between the overturning moment and wind speed range is very similar for all the shear conditions, reaching a peak at a rated wind speed in all cases. Figure 13 shows the maximum shear condition for yaw angles $0^{\circ}$ and $\pm 8^{\circ}$. In horizontal positive Extreme Wind Shear (EWSH+), the maximum overturning moment $9,056 \mathrm{E}+07 \mathrm{Nm}$ is observed at rated wind speed. This DLC results in lower loads than the previous ones and a wind speed of $12 \mathrm{~m} / \mathrm{s}$ is observed to lead to a higher overturning moment. The results show that there is no clear correlation between yaw angle or the initial azimuth angle of blade 1 and the overturning moment, as is shown in Figure 14.

The pitch controller delay is also analysed as shown in Figure 15. The maximum overturning moment occurs after approximately 15 seconds of the shear peak, this is because during the shear the blades pitch which changes the angle of attack. When wind speed decreases back to the original value the pitch angle starts a damped oscillation, when it reaches a trough the blades are almost feathered causing the highest resistance to the wind and thus the highest overturning moment. This DLC does not cause the highest flapwise or edgewise moment, but this small variation does affect the blade response. The shear events causing the highest flapwise response for all the yaw misalignments are EWSH- and EWSV+ leading to a peak of approximately $1.3 \mathrm{E}+04 \mathrm{kNm}$ at a rated wind speed as seen in Figure 16 . A small correlation with yaw angle is observed with $+8^{\circ}$ yaw misalignment leading to higher loads. No relevant correlation with blade 1 initial azimuth angle is seen. On the other hand, the EWH- causes the highest edgewise moment for all yaw misalignments having always the peak at rated wind speed. Negative yaw misalignment always creates the worst scenario, but only by a small amount. As with the flapwise moment, there is no correlation with the initial azimuth angle of blade 1 as can be seen from Figure 16. In Figure 17 the comparison between the maxima of the 
4 wind shear events at rated wind speed is shown; these values also correspond to the maxima of this DLC and show that the EWSH+ causes a higher overturning moment whereas EWSproduces higher flapwise and edgewise moments.

\subsubsection{DLC 1.6a}

DLC 1.6a follows the Severe Sea State (SSS) with a significant wave height $H_{S}=H_{S, S S S}(V)$, it is recommended to use the unconditional extreme significant wave height $H_{S 50}$ with a recurrence period of 50 years as a conservative value for $\mathrm{H}_{\mathrm{S}, \mathrm{SSS}}(\mathrm{V})$ [1]. Hence, $\mathrm{H}_{\mathrm{S} 50}$ is used, implying that the significant wave height does not vary between different wind bins. The significant wave height for a 1-hour simulation period may be obtained from the value corresponding to a 3-hour reference period [1] using a conversion factor of 1.09. The current model is Normal Current Model (NCM) but water level changes to the Normal Water Level Range (NWLR). The simulations are performed with the highest water level within the NWLR which is the Highest Astronomical Tide (HAT). The total number of simulations implied for this DLC is then 198 (11 wind speed bins x 6 seeds x 3 yaw angles). Figure 18 shows how the overturning moment follows the same shape as in the previous DLCs leading to higher values for wind speeds close to rated, the difference between the results for the last wind bins is smaller as higher waves tend to homogenise the structural response. The wind bin with the higher mean of maxima (dashed line) corresponds to a wind speed of $12 \mathrm{~m} / \mathrm{s}$, the rated wind speed, with $\pm 8^{\circ}$ yaw misalignment. The same pattern is repeated for the flapwise and edgewise moments.

A random seed corresponding to $12 \mathrm{~m} / \mathrm{s}$ is chosen to identify the cause of the maximum overturning moment and the results in Figure 19 show how this DLC is dominated by waves, the maximum comes after 446 seconds and it is caused by a big train of waves. In fact, during this sequence of high waves, the overturning moment is highly correlated reaching local maxima after each big wave. Moreover, in Figure 20 it is seen how the flapwise moment oscillates due to the variation in the wind speed, with the pitch controller also contributing to diminish the flapwise moment. The oscillations of the pitch angle show the moments at which the wind speed goes above rated. The edgewise moment oscillates almost uniformly independently of all the other variables as there is no directional change of the wind speed. The generator torque controller follows the same pattern as the rotor speed as the former controls the latter.

\subsection{Parked (standing still or idling) DLCs}

In this design situation the rotor is either in a standstill or idling condition. In order to model this situation in FAST the initial conditions of pitch angle and angular speed must be changed, to do that the ElastoDyn parameter BldPitch is set to a feathered position $\left(90^{\circ}\right)$ and the rotor speed RotSpeed to $0 \mathrm{rpm}$. Additionally, in the ServoDyn input the pitch control is deactivated by setting PCMode to 0, the generator will never work by setting GenTiStr to "TRUE" and TimGenOn to a number high enough such as 9999.9 to assure that it will never be activated. The unsteady aerofoil aerodynamics (BEDDOES) calculations in AeroDyn are only valid in operational conditions, not at the very high angles of attack that would be experienced in parked/idling conditions. Hence the stall model StallMod must be switched to "STEADY" and also the induction-factor model must be disabled by setting IndModel to "NONE".

The DLCs analysed with regard to this design situation are 6.1a and 6.2a. IEC 61400-3 states that the load cases $6.1 \mathrm{~b}, 6.1 \mathrm{c}, 6.2 \mathrm{~b}$ and $6.2 \mathrm{c}$ can be omitted if the nonlinear wave kinematics can be accounted in the treatment of $6.1 \mathrm{a}, 6.2 \mathrm{a}$ and $6.2 \mathrm{~b}$. In this work, we have not considered $6.1 \mathrm{~b}$, $6.1 \mathrm{c}, 6.2 \mathrm{~b}$ and $6.2 \mathrm{c}$. The implications of including nonlinear wave kinematics will be considered 
in future work. The DLCs 6.3a and 6.3b which account for an extreme yaw misalignment, are not included as they are simulated implicitly by DLC 6.2a since the loss of electrical network is simulated by reproducing 12 yaw misalignments (at every $30^{\circ}$ ). It is to be noted that as these DLCs deal with very high winds the design load is greatly influenced by the wind drag force over the tower.

\subsubsection{DLC 6.1a}

TurbSim provides an Extreme Wind Model (EWM) for every wind turbine class, but it is only valid for 10-minute simulations thus it is not useful to simulate this DLC. The generation of turbulent wind for EWM model is achieved for 1-hr simulations by setting the IEC_WindType as "NTM" in TurbSim, and manually specifying the desired turbulence intensity as $11 \%$ by using the parameter IECturbc option.

As for the other DLCs, simulations are carried out with 0 and $\pm 8^{\circ}$ representing the possible delay of a yaw controller. Also the simulations are run in three blocks 0 and $\pm 30^{\circ}$ of wind/wave misalignment. Note that since the foundation structure is a monopile, the axisymmetry of the structure restricts the wind-wave misalignment combinations. The near surface current is increased to $1.2 \mathrm{~m} / \mathrm{s}$ following the Extreme Current Model (ECM) and the water level must be within the Extreme Water Level Range (EWLR), for this DLC the Highest Still Water Level (HSWL) is used as it represents the highest water level within the range. The combinations for this DLC lead to 54 simulations ( 6 seeds $\times 3$ wind/wave angle $x 3$ yaw angles). Figure 21 shows the relevance of the yaw angle and wind/wave misalignment against the overturning, flapwise and edgewise moments. It allows one to realise that for the flapwise and edgewise moments the wind/wave misalignment does not really have a relevant role, whereas the yaw angle does affect the results. The pattern of the three yaw angles is repeated for each wind/wave misalignment, the negative yaw angle leads to higher loads in the three wind/wave conditions followed by the $+8^{\circ}$ yaw angle. It is also seen that the condition with lower loads corresponds to $0^{\circ}$, except for the edgewise moment with $-30^{\circ}$ wave/wind angle, where the highest load comes with the positive yaw angle. The overturning moment behaves differently as it is affected by both the wind/wave misalignment and yaw angle, with higher loads observed at opposite signs of yaw and wind/wave angle.

The time-series of the main parameters corresponding to a seed with $-8^{\circ}$ yaw angle and $30^{\circ}$ of wind/wave misalignment are plotted in Figure 22. In this DLC the wind effect is considerably high, although the peaks of the overturning moment occur when high waves appear. The maximum of the time-series of Figure 22 appears after 2625 seconds of simulation, during the occurrence of a wave of approximately $13 \mathrm{~m}$ height. Also, the oscillation frequency for the edgewise moment is quite higher than the flapwise moment; both are mainly only influenced by wind speed.

\subsubsection{DLC 6.2a}

This DLC aims to simulate a special event which is the loss of network of the wind turbine; it means that if the turbine does not have a battery backup of the yaw drive it will lose the control over it. The way to model this extra condition is by running the simulations for the full range of possible yaw misalignment angles, which is $\pm 180^{\circ}$, leading to a total number of 216 simulations ( 6 seeds $\mathrm{x} 12$ yaw angles $\mathrm{x} 3$ wind/wave angles). To modify the yaw angle in FAST one has to change the initial conditions in ElastoDyn by setting the parameter NacYaw to the desired angle, and simultaneously the YawNeut parameter in ServoDyn must be also set to the same angle, 
otherwise the restoring spring would be acting to rotate the rotor and nacelle towards the neutral angle.

It is important to highlight that when using FAST there is an instability that occurs for the NREL baseline turbine at around $\pm 30^{\circ}$ degrees. This is described as an "aero-elastic interaction causing negative damping in a mode that couples rotor azimuth with platform yaw" [24]. The current approach by the industry to deal with this problem is either to bypass it by choosing yaw errors that do not result in the instability or increase the structural damping in the blade edge/tower side-to-side mode until the instability disappears. In the present work, the first option is considered by ignoring the case that causes the instability.

The $30^{\circ}$ wind/wave misalignment seems to create a slightly higher overturning moment for $60^{\circ}$ yaw angle and therefore a random seed of this combination is used to study this DLC. The overturning moment at the seabed, the flapwise and edgewise moments at the root of blade 1 , rotor thrust (in the direction of the mean wind, regardless of the yaw error) and shear force at the top of the tower are plotted in Figure 23 for $30^{\circ}$ wind/wave misalignment, all yaw angles with corresponding maxima for all the 6 seeds. The instability commented before is reflected in the variability of these three parameters at $\pm 30^{\circ}$ of yaw angle, although some of these values are not plotted here. The minima and maxima of the shear force values include structural oscillations of the rotor-nacelle weight/inertia, but the weight/inertia should not impact the mean values much. As expected, the maximum tower shear occurs for $90^{\circ}$ yaw error, where the incoming wind is normal to the chord when the blades are pitched to $90^{\circ}$. FAST calculates the rotor loads for these cases; however a bigger part of the load is the direct wind load on the tower, which dominates the rotor loads during this condition for most yaw errors. The effect of tower drag loading is seen on the overturning moment at the seabed level. From Figure 24, it is seen that the behaviour is similar to DLC 6.1a as large wave trains seem to dominate local maxima of the overturning moment, although the highest value occurs when a large wave and a wind speed peak occur simultaneously.

\section{DISCUSSION OF RESULTS}

\subsection{Safety factors}

This section aims to compare the results obtained in the previous sections, with a view to rank the considered DLCs, and hence identify the most severe DLC in terms of its effect on the support structure. For each DLC, the design load is deduced by applying recommended factors of safety on the characteristic loads obtained from the simulations. As specified in IEC 61400-3 for DLCs with deterministic wind field and wave events, the characteristic value of the load effect shall be the worst case computed transient value. If turbulent inflow is used together with irregular sea states, the mean value among the worst case computed load effects for different stochastic realisations shall be taken. If this is applied to the DLCs analysed with in this report, DLCs 1.4 and 1.5 are included in the first group, whereas for DLCs 1.1, 1.3, 1.6a, 6.1a and 6.2a the characteristic load is obtained as the highest average (over 6 seeds) of all cases. Table 6 indicates the partial safety factors required for each DLC, stated in IEC 61400-3. For the ULS DLCs within power production situation the normal partial safety factor of 1.35 is assigned, except for DLC 1.1 in which 1.25 must be used as the loads are determined using statistical extrapolation. In the case of ULS parked DLCs a normal safety factor of 1.35 is required except for DLCs 6.2 in which the loss of electrical network is combined with the 50-year return wind and wave conditions. As this combined event has a lower probability of occurrence, an 
abnormal partial safety factor of 1.1 is assigned. Table 6 shows the obtained design values for the overturning moment at the mudline and flapwise moment at the root of the blade.

\subsection{Structural response}

The set of values of the overturning moment at the seabed level, flapwise and edgewise moments for all DLCs was created, sorted from the largest to the smallest and shown in Figure 25 . It is observed that DLC 1.6 a leads to the highest design overturning moment of $1.77 \mathrm{E}+08 \mathrm{Nm}$, followed by DLC 1.4 in which the result is $7.34 \%$ lower. The least demanding DLC is 1.5 . For the edgewise and flapwise moments the ranking follows a very similar pattern, the DLC causing the highest design loads is 1.4 followed by 1.1 and 1.3, although for the flapwise moment the difference between 1.4 and the others is much bigger (21.25\%) than for the edgewise moment, where the difference is only $8.6 \%$.

It is useful to understand and compare the real influence and contribution of the hydrodynamic loading and the tower top Fx force to the overall structure response, as shown in Figure 26. Firstly, it is interesting to see how the largest negative values of the hydrodynamic moment at the seabed level are larger than the positive ones. However, this effect is rather positive for the structure as it opposes the main $x$-positive loading and helps damping the structure and reducing the overturning moment. On the other hand, it can be seen that DLCs 1.6a, 6.1a and 6.2a are more hydrodynamically loaded than the others, and despite having lesser tower top loading two of them (1.6a and 6.2a) are in the top 3 of the ranking. Therefore, the design of this structure is driven by the hydrodynamic loading.

Also, the position of DLC 1.4 for the 3 studied parameters is remarkable, as the use of deterministic wind field captures two negative effects at same time. First, the wind gust together with the delay on the pitch controller creates a large overturning and flapwise moment, and secondly, it shows how the wind rotation leads to the severest response of the edgewise moment. In addition, the effect of the pitch controller on the structural response and its role in driving the design loads must be carefully noted. The overturning and flapwise moments show a significant high correlation with the pitch angle in power production DLCs, meaning that sharp variations in the latter lead to critical design situations. Hence, improvements in the pitch controller such as individual pitch control $[25,26]$ or anticipating the wind troughs $[27,28]$ would directly diminish the design loads.

\section{Conclusions}

We have conducted a systematic comparative study of the power production and parked load cases proposed by the IEC 61400-3 as those load cases are most likely to cause design driving loads for OWT support structures. The analysis is conducted on a prototypical turbine mounted on a monopile structure. The metocean parameters are extracted from a well-known database. The key parameter for the design of the support structure is identified as the overturning moment at the mudline level, and for the blade design, the flapwise and edgewise moments at the blade root. The simulations are carried out using FAST. The structural response to different ultimate limit states is analysed and the DLCs are ranked based on these three parameters to provide guidance to other researchers and industry for designing these structures. The hydrodynamic loading is proven as the design driving load for the support structure as maximum overturning moment is reached in DLC 1.6a, whereas a wind gust together with a wind direction change is the situation causing both the highest flapwise and edgewise moments. 
537 Some complications derived from the code instabilities are addressed and solutions are 538 proposed. The results of our work will be useful as starting points for detailed study of the 539 relevant load cases, as well as to conduct reliability analyses for various limit states for the 540 substructure. While we believe that the considered load cases in this study are comprehensive 541 to cover substructure design, future work will address the transient load cases (faults, startup 542 and shutdown). Future work will also shed light on the sensitivity of the conclusions of the 543 present work to metocean conditions, water depths and monopile geometry.

\section{Acknowledgments}

545 This PhD research is funded by Lloyd's Register Group Services Ltd., Aberdeen. Sriramula's 546 work within the Lloyd's Register Foundation Centre for Safety and Reliability Engineering at the 547 University of Aberdeen is supported by Lloyd's Register Foundation. The Foundation helps to 548 protect life and property by supporting engineering-related education, public engagement and 549 the application of research. We would also like to acknowledge the constant assistance provided 550 by Jason Jonkman on using FAST.

$\begin{array}{ll}\text { CDF } & \text { Cumulative Distribution Function } \\ \text { DLC } & \text { Design Load Case } \\ \text { DLL } & \text { Dynamic Link Library } \\ \text { ECD } & \text { Extreme Coherent gust with direction Change } \\ \text { ECM } & \text { Extreme Current Model } \\ \text { ESS } & \text { Extreme Sea State } \\ \text { ETM } & \text { Extreme Turbulence Model } \\ \text { EWM } & \text { Extreme Wind Model } \\ \text { EWS } & \text { Extreme Wind Shear } \\ \text { GDW } & \text { Generalized-Dynamic Wake } \\ \text { HAT } & \text { Highest Astronautical Tide } \\ \text { HSWL } & \text { Highest Still Water Level } \\ \text { MSL } & \text { Mean Sea Level } \\ \text { NCM } & \text { Normal Current Model } \\ \text { NREL } & \text { National Renewable Energy Laboratory } \\ \text { NSS } & \text { Normal Sea State } \\ \text { NTM } & \text { Normal Turbulence Model } \\ \text { OC3 } & \text { Offshore Code Comparison Collaboration } \\ \text { OWT } & \text { Offshore Wind Turbine } \\ \text { RECOFF } & \text { Recommendations for Offshore wind turbines design } \\ \text { SSS } & \text { Severe Sea State } \\ \text { ULS } & \text { Ultimate Limit State }\end{array}$


[1] IEC, (2009). IEC 61400-3: Wind Turbines-Part 3: Design Requirements for offshore wind turbines, International Electrotechnical Commission, Geneva.

[2] IEC, (2005). IEC 61400-1: Wind Turbines-Part 1: Design Requirements, International Electrotechnical Commission, Geneva.

[3] Frandsen, S., Tarp-Johansen, N.J., Norton, E., Argyriadis, K., Bulder, B. and Rossis, K., (2005). Recommendations for design of offshore wind turbines, Report No. Final Technical Report, Ris $\varnothing$ National Laboratory, Roskilde, Denmark.

[4] Norton, E. and Quarton, D., (2003). Recommendations for design of offshore wind tubines (RECOFF), D3 Deliverable-Collated Sensitivity Studies, Document No, 2762.

[5] Tarp-Johansen, N.J., (2005). Partial Safety Factors and Characteristic Values for Combined Extreme Wind and Wave Load Effects, Journal of Solar Energy Engineering, 127 (2), pp.242-252.

[6] Tarp-Johansen, N., Manwell, J. and McGowan, J., (2006). Application of design standards to the design of offshore wind turbines in the US, Offshore Technology Conference, Houston, Texas.

[7] Stewart, G., Lackner, M., Haid, L., Matha, D., Jonkman, J. and Robertson, A., (2013). Assessing fatigue and ultimate load uncertainty in floating offshore wind turbines due to varying simulation length, 11th International Conference on Structural Safety and Reliability; Columbia University, New York, New York;

[8] Agarwal, P. and Manuel, L., (2007). Simulation of offshore wind turbine response for extreme limit states, June 16-20, 2013.

[9] Agarwal, P., (2008). Structural Reliability of Offshore Wind Turbines, B.Tech., M.S. The University of Texas at

[10] Moriarty, P.J., Holley, W. and Butterfield, C.P., (2004). Extrapolation of extreme and fatigue loads using probabilistic methods, Report No. NREL/TP-500-34421, Cole Boulevard, Golden, Colorado: Citeseer.

[11] Cheng, P.W., (2002). A reliability based design methodology for extreme responses of offshore wind turbines, TU Delft, Delft University of Technology.

[12] Vermula, N.K., (2010). Deliverable D4.2.5 - WP4.2: Offshore foundations and support structures, UpWind project.

[13] De Vries, W., (2011). Deliverable D4.2.8 - WP4.2: Offshore foundations and support structures, UpWind project.

[14] Kim, B., Jin, J., Bitkina, O. and Kang, K., (2015). Ultimate load characteristics of NREL 5-MW offshore wind turbines with different substructures, International Journal of Energy Research.

[15] Cordle, A., McCann, G. and de Vries, W., (2011). Design drivers for offshore wind turbine jacket support structures, ASME 2011 30th International Conference on Ocean, Offshore and Arctic Engineering, pp. 419428.

[16] Morató Casademunt, A., Sriramula, S. and Krishnan, N., (Sept 2016). Reliability analysis of offshore wind turbine support structures using kriging models, Safety and Reliability of Complex Engineered Systems, ESREL 2016, Glasgow, UK. 
[17] Galinosa, C., Larsena, T.J., Madsena, H.A. and Paulsena, U.S., (January 2016). Vertical axis wind turbine design load cases investigation and comparison with horizontal axis wind turbine, Deep Sea Offshore Wind R\&D Conference. DeepWind' 2016, Trondheim, Norway.

[18] Jonkman, J.M. and Buhl, M.L.J., (Updated August 2005). FAST user's guide - Technical report NREL/EL-50038230 national renewable energy laboratory, Report No. 144 pp, Colorado, USA.

[19] Jonkman, B.J., (2009). TurbSim User's Guide: Version 1.50. National Renewable Energy Laboratory Golden, CO, USA.

[20] Jonkman, J. and Musial, W., (2010). Offshore Code Comparison Collaboration (OC3) for IEA Wind Task 23 Offshore Wind Technology and Deployment. National Renewable Energy Laboratory (NREL), Golden, CO.

[21] Jonkman, J.M., Butterfield, S., Musial, W. and Scott, G., (2009). Definition of a 5-MW reference wind turbine for offshore system development, Report No. NREL/TP-500-38060, Colorado, USA: National Renewable Energy Laboratory.

[22] Fischer, T., De Vries, W. and Schmidt, B., (2010). UpWind design basis (WP4: Offshore foundations and support structures), Project UpWind.

[23] Moriarty, P.J. and Hansen, A.C., (2005). AeroDyn theory manual, Report No. NREL/TP-500-36881, 1617 Cole Boulevard, Golden, Colorado 80401-3393: National Renewable Energy Laboratory.

[24] Skrzypiński, W., (2012). Analysis and modeling of unsteady aerodynamics with application to wind turbine blade vibration at standstill conditions.

[25] Bossanyi, E., (2003). Individual blade pitch control for load reduction, Wind Energy, 6 (2), pp.119-128.

[26] Liu, H., Wang, Y., Tang, Q. and Yuan, X., (2015). Individual pitch control strategy of wind turbine to reduce load fluctuations and torque ripples, International Conference on Renewable Power Generation (RPG 2015), pp. 1-5.

[27] Dunne, F., Simley, E. and Pao, L., (2011). LIDAR wind speed measurement analysis and feed-forward blade pitch control for load mitigation in wind turbines, National Renewable Energy Laboratory, Golden, CO.

[28] Schlipf, D., Kapp, S., Anger, J., Bischoff, O., Hofsäß, M., Rettenmeier, A. and Kühn, M., (14-17 March 2011). Prospects of optimization of energy production by lidar assisted control of wind turbines, EWEA 2011 Conference Proceedings, Brussels, Belgium. 


\section{FIGURES}

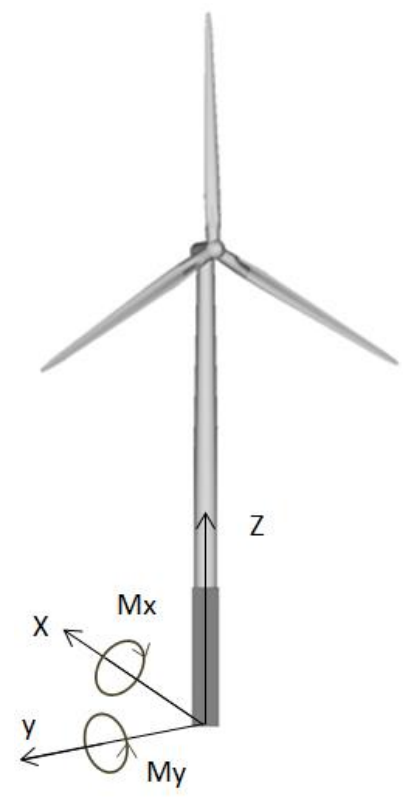

Figure 1 - Coordinate system for the overturning moment.

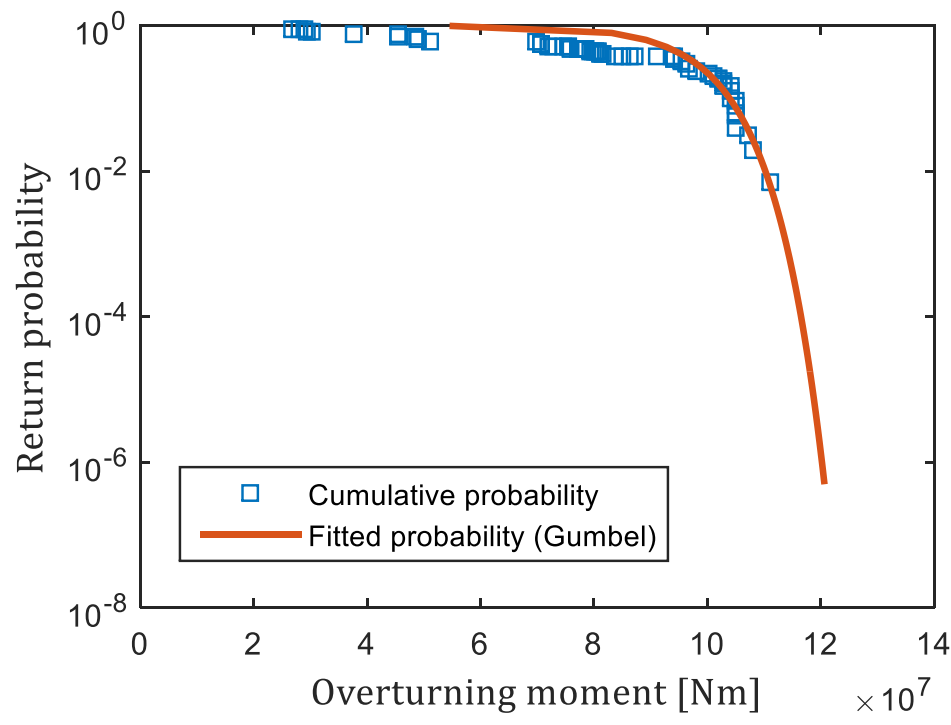

Figure 2 - Extrapolation of the overturning moment at the seabed 

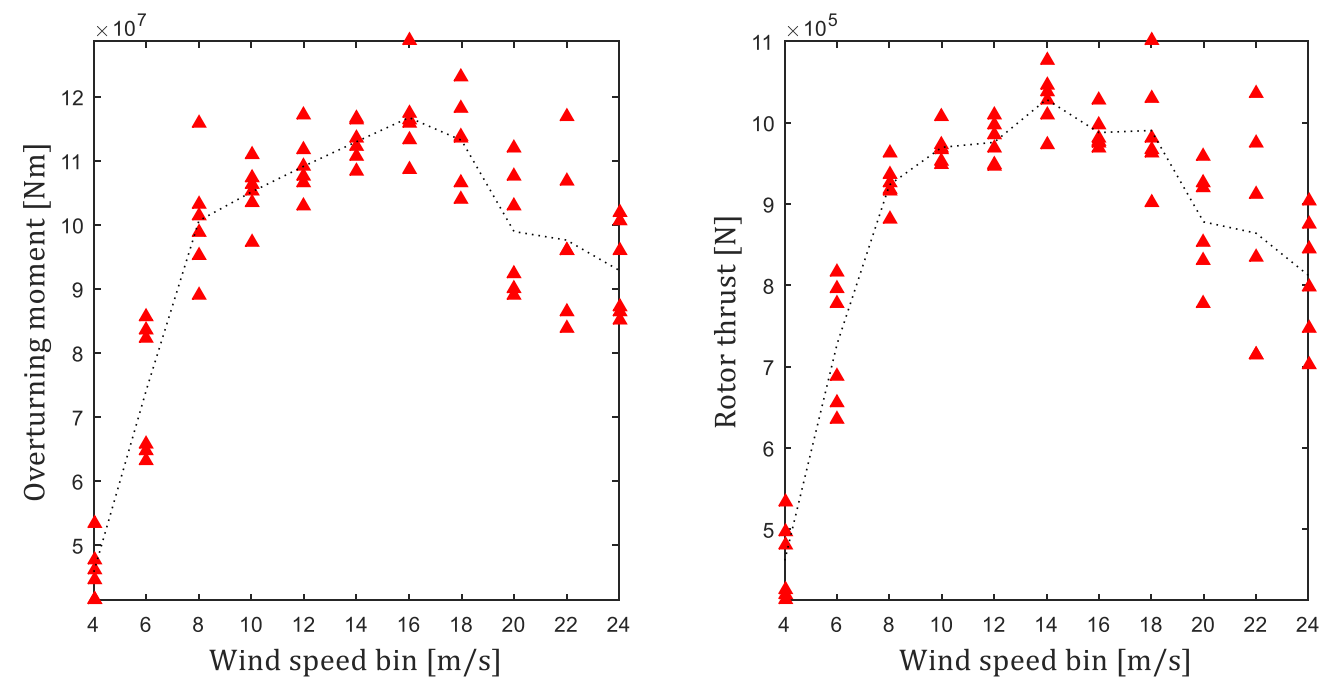

Figure 3 - Maximum values of the 6-seed-maxima for each wind speed bin: overturning moment on the left and Rotor thrust on the right. The dashed line corresponds to the mean of the characteristic load for each wind bin. These values relate to DLC 1.3 and a yaw misalignment of $8^{\circ}$.
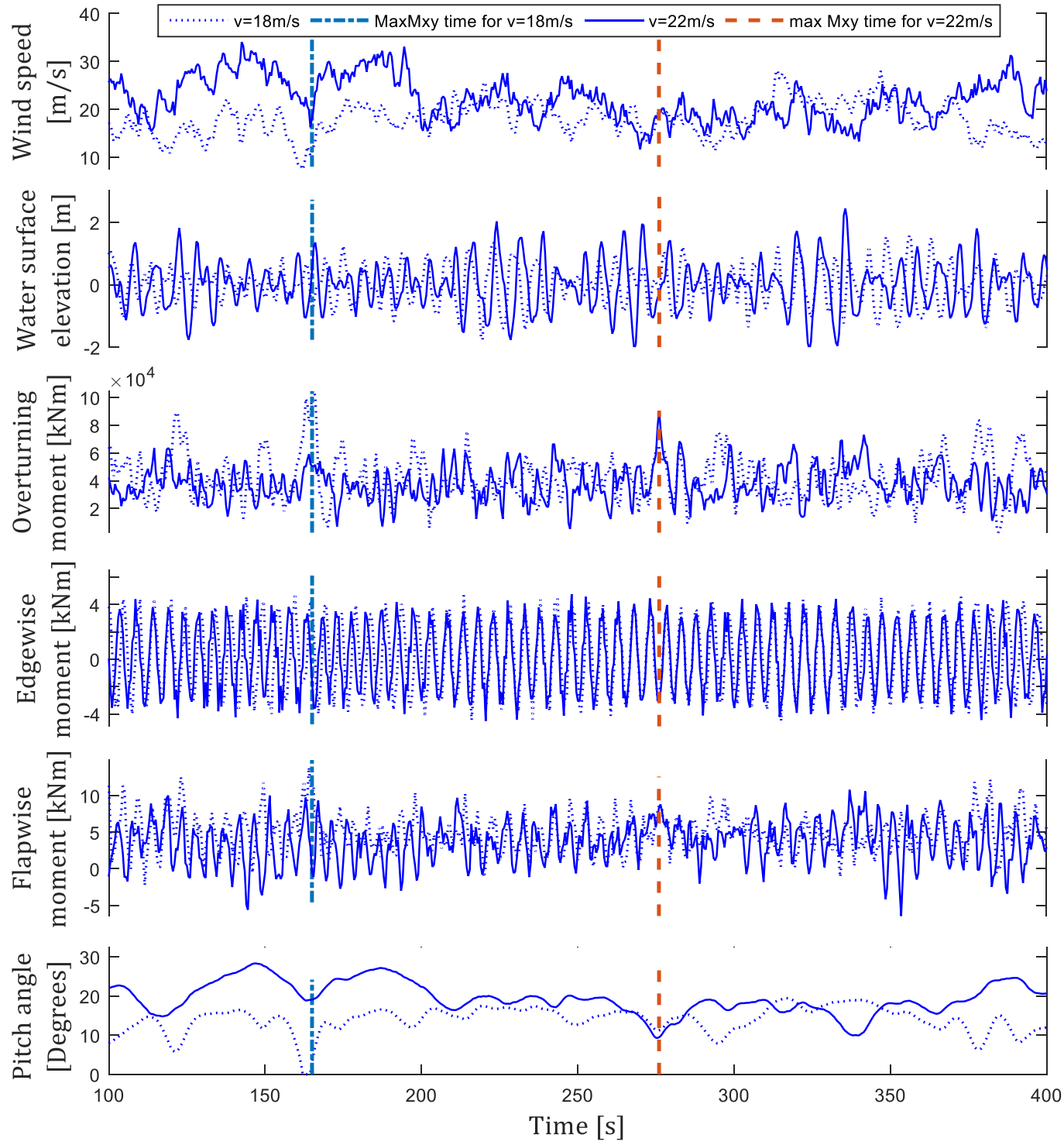

Figure 4-DLC 1.3 time-series of wind speed, water surface elevation, overturning moment, edgewise and flapwise moment and pitch angle of blade 1 for the seed 4 of wind bin $18 \mathrm{~m} / \mathrm{s}$ and seed 3 of wind bin $22 \mathrm{~m} / \mathrm{s}$, both with $-8^{\circ}$ yaw misalignment. 

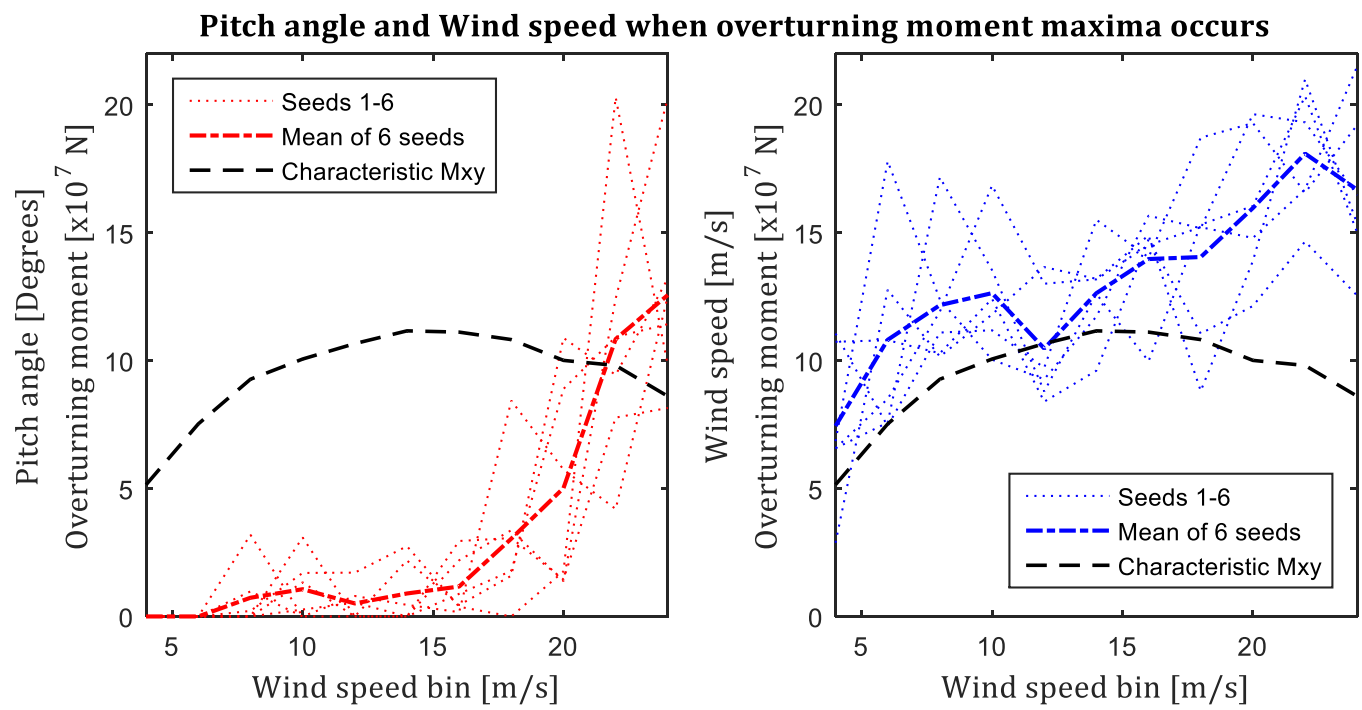

Figure 5 - Pitch angle and wind speed for each seed corresponding to maximum overturning moment

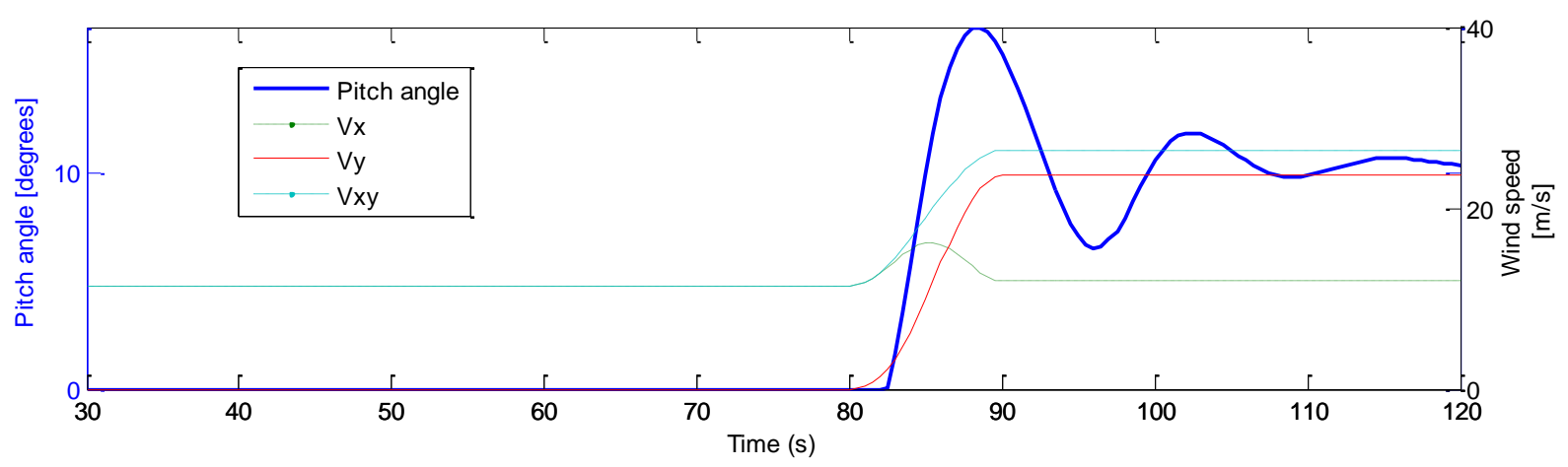

Figure 6 - Variation of wind speeds and pitch angle for ECD-r 

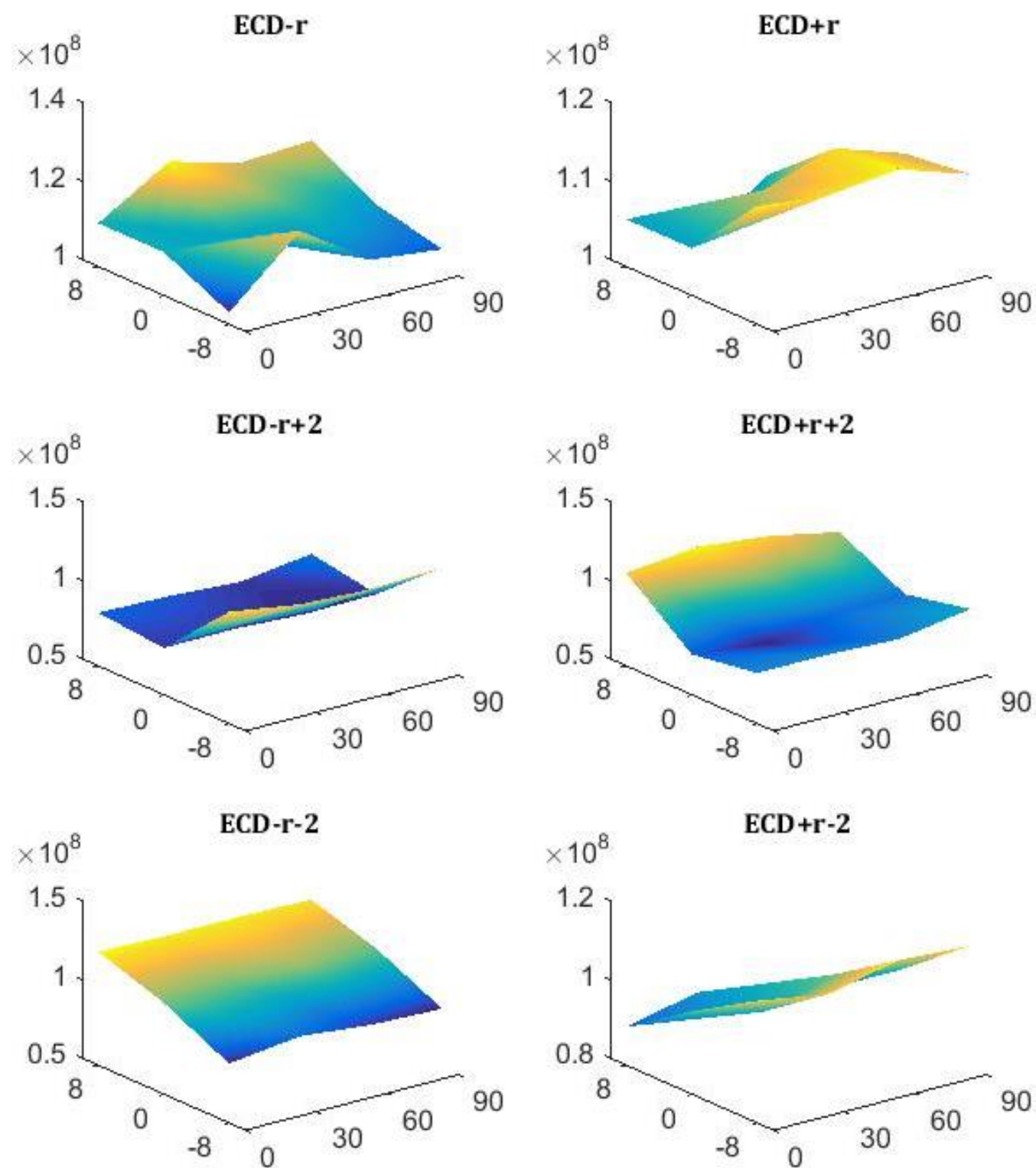

Figure 7-Comparison of the correlation between overturning moment at seabed, initial azimuth angle of blade $(0,30,60$ and $90^{\circ}$ ) and yaw misalignment $\left(0 \pm 8^{\circ}\right)$.

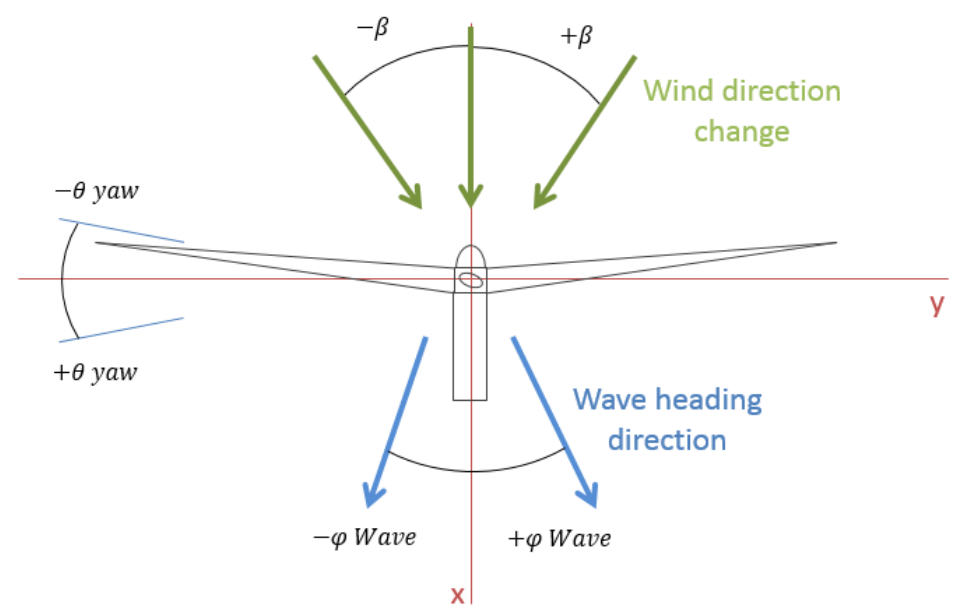

Figure 8-Coordinate system, positive and negative rotations 


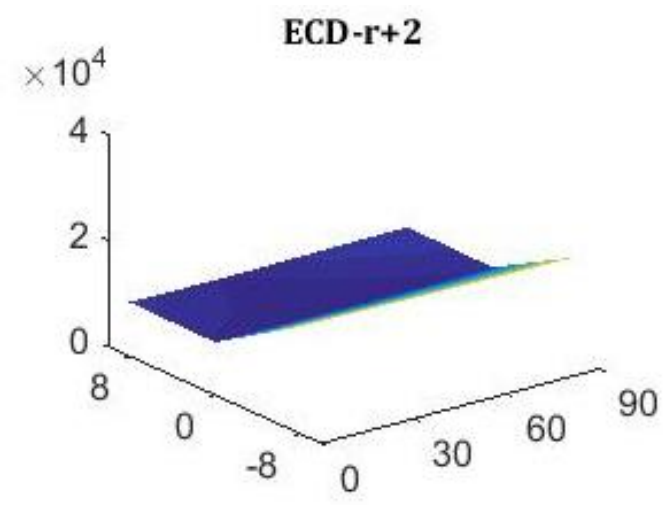

ECD-r

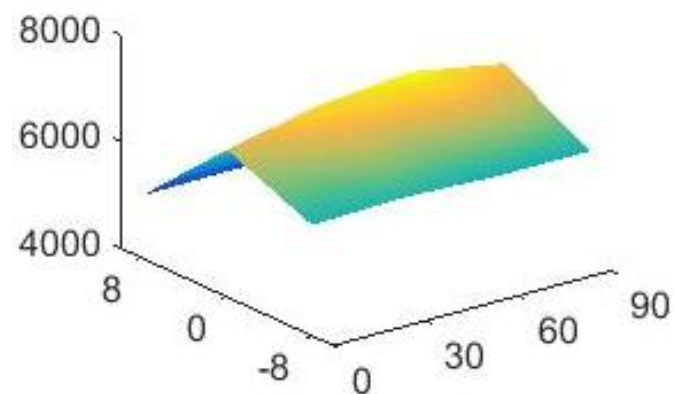

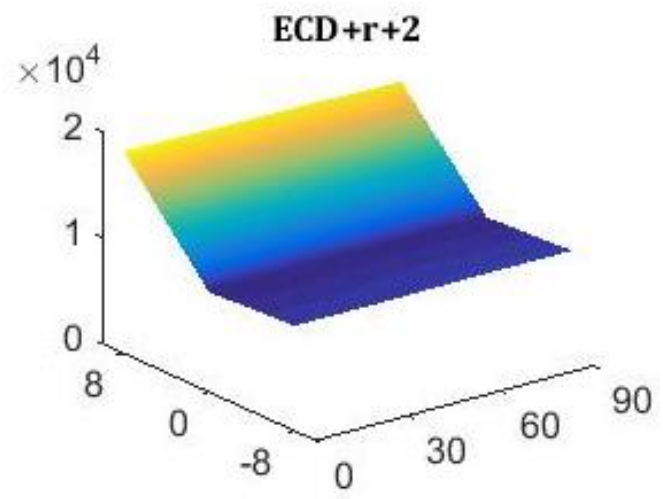

ECD-r+2

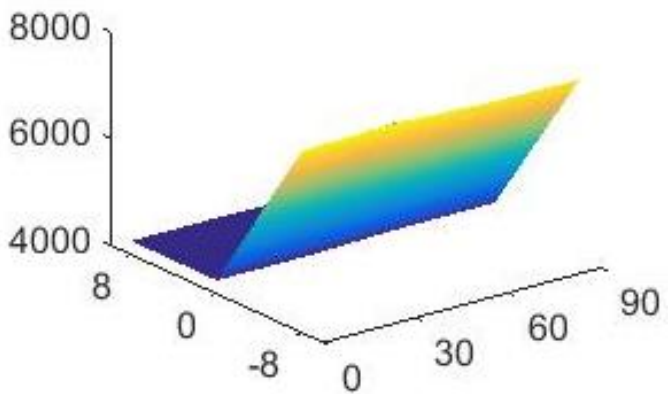

Figure 9 - Highest wind conditions for Flapwise and Edgewise moment as a function of the yaw angle $\left(0 \pm 8^{\circ}\right)$ and the initial azimuth angle of blade $1\left(0,30,60\right.$ and $\left.90^{\circ}\right)$. Top row ECD-r+2 (left) and ECD $+r+2$ (right), lower row ECD-r (left) and ECD-r+2 (right).

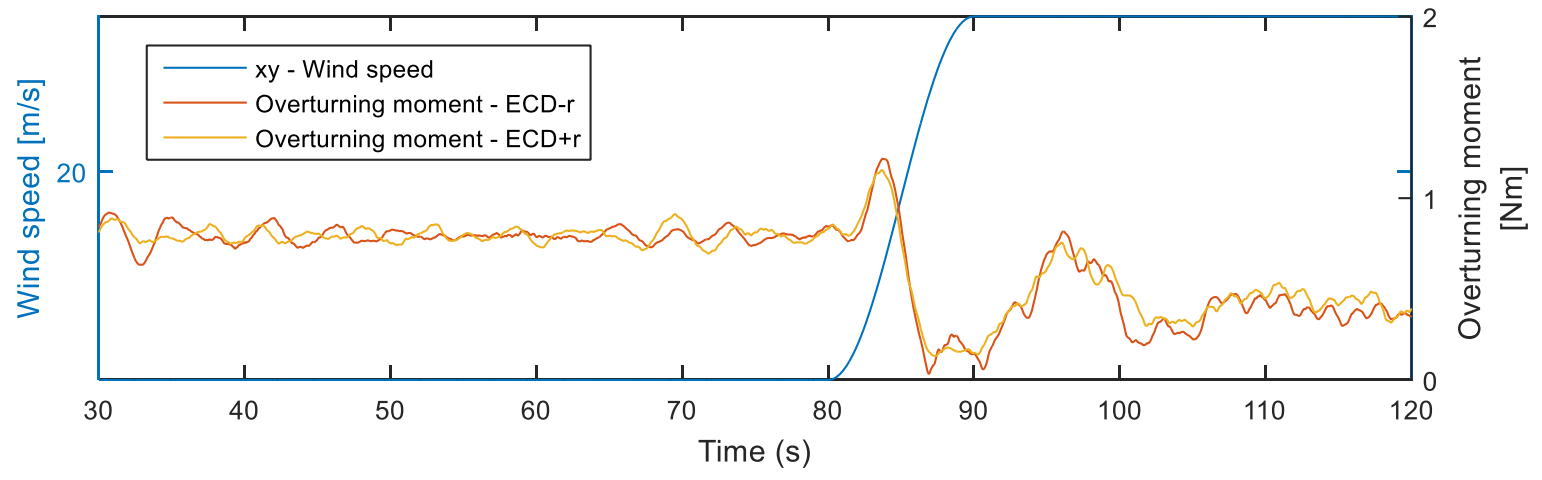

Figure 10 - Reaction of the overturning moment due to $E C D \pm r$

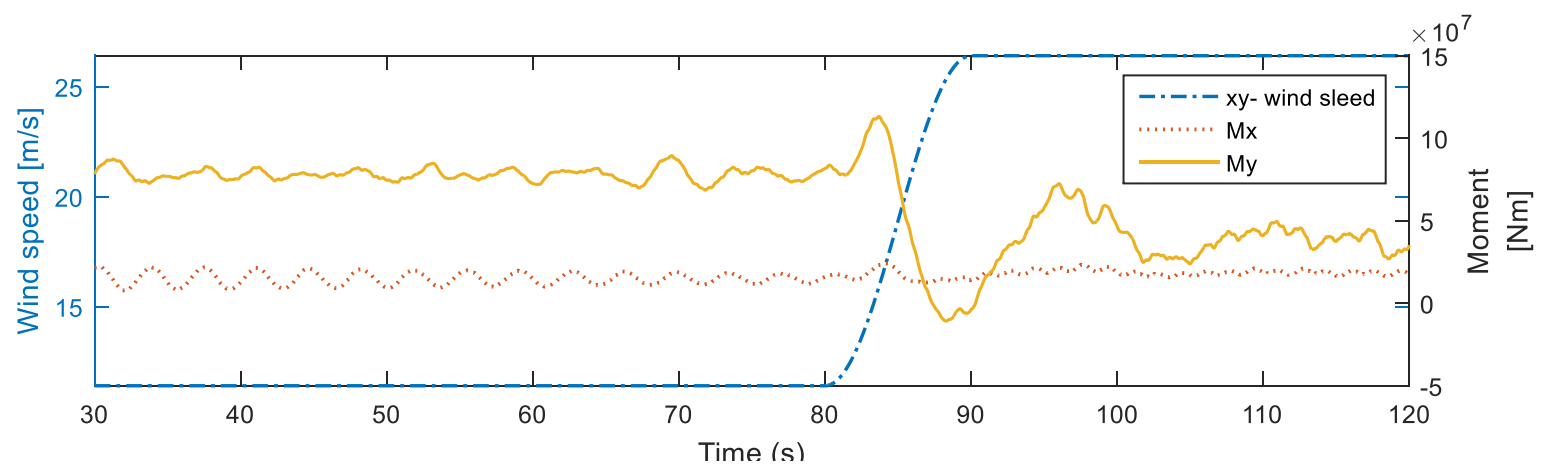

Figure 11 - Comparison of reaction of $M x$ and $M y$ at seabed due to ECD+r 

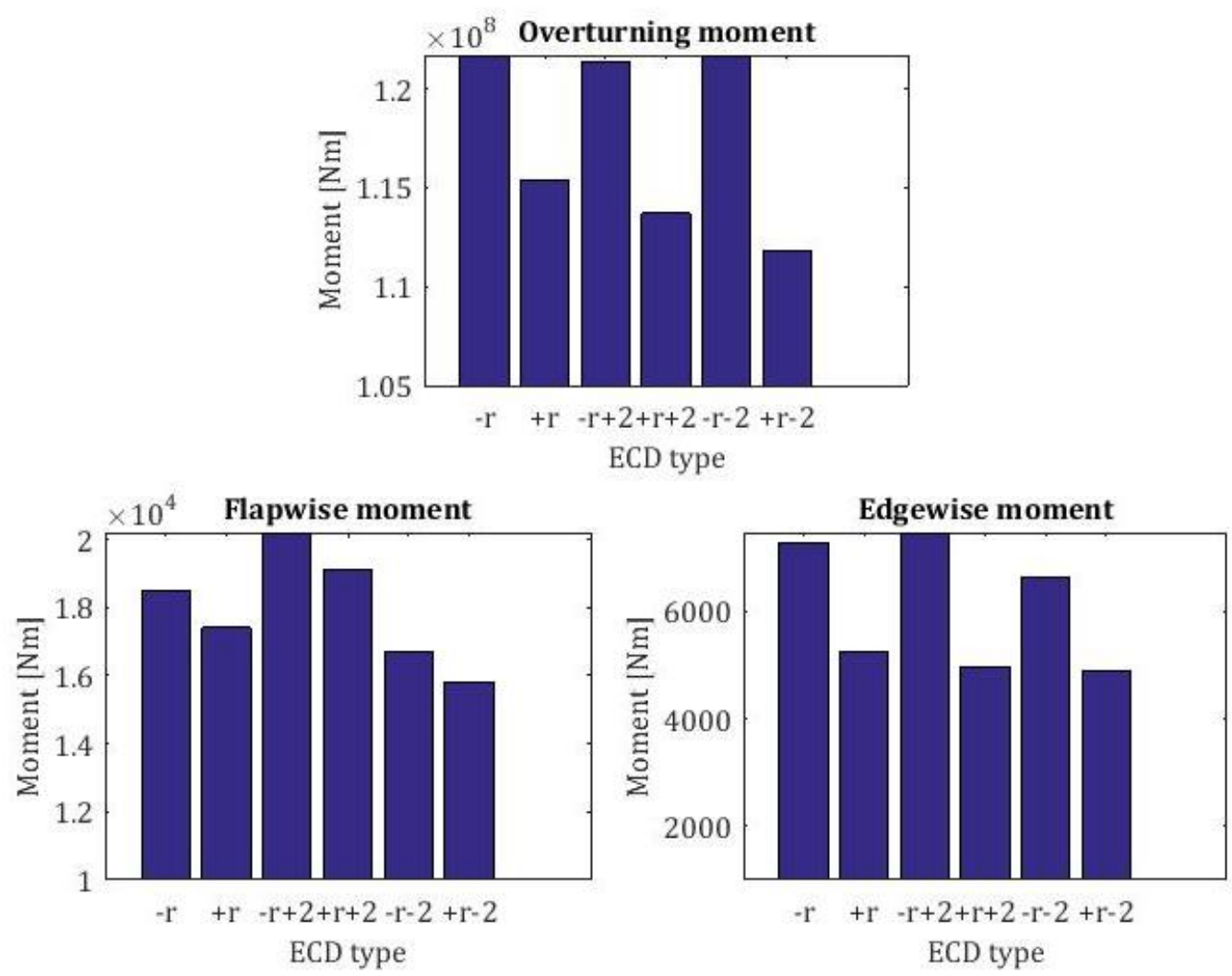

Figure 12 - Comparison the maximum overturning, flapwise and edgewise moment reach for all situations of DLC 1.4.

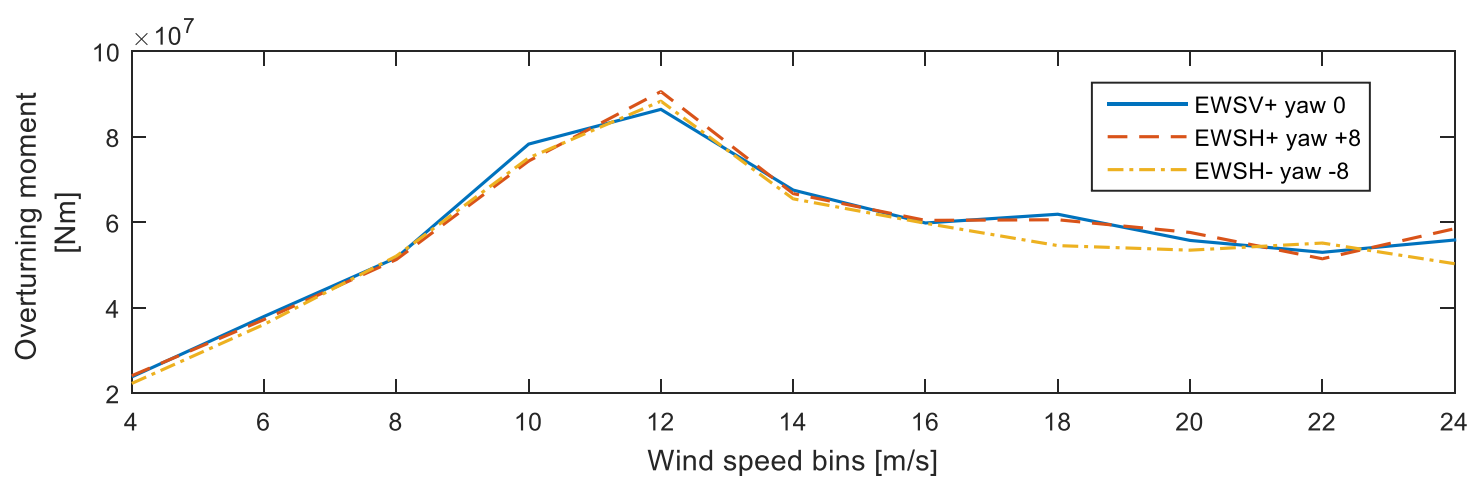

Figure 13 - Evolution of overturning moment at seabed for the worst case of each yaw angle. 

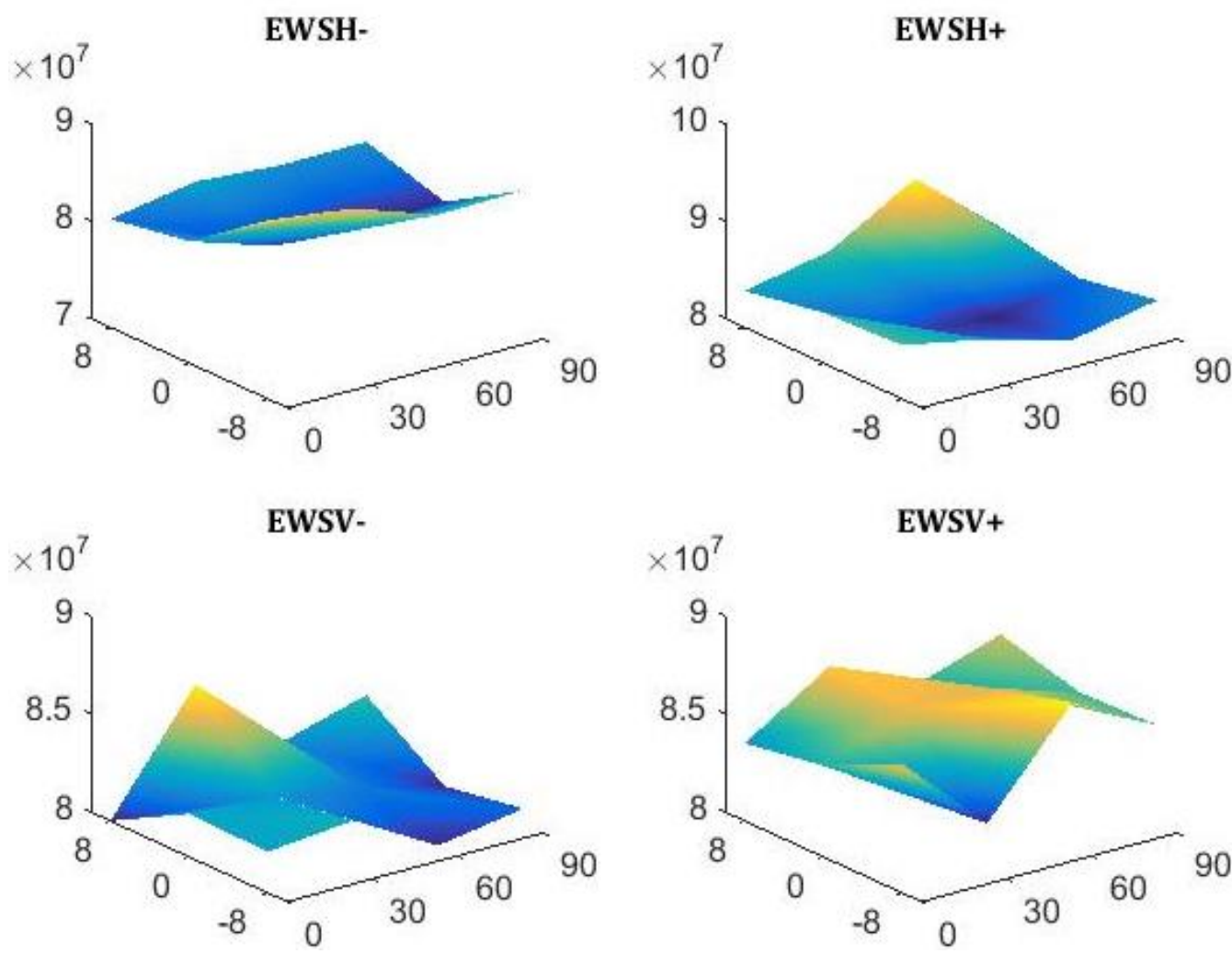

Figure 14 - Correlation between yaw angle $\left(0 \pm 8^{\circ}\right)$, initial azimuth angle of blade $1\left(0,30,60\right.$ and $\left.90^{\circ}\right)$ and overturning moment $(N \cdot m)$ for the four wind shears of $12 \mathrm{~m} / \mathrm{s}$ wind bin
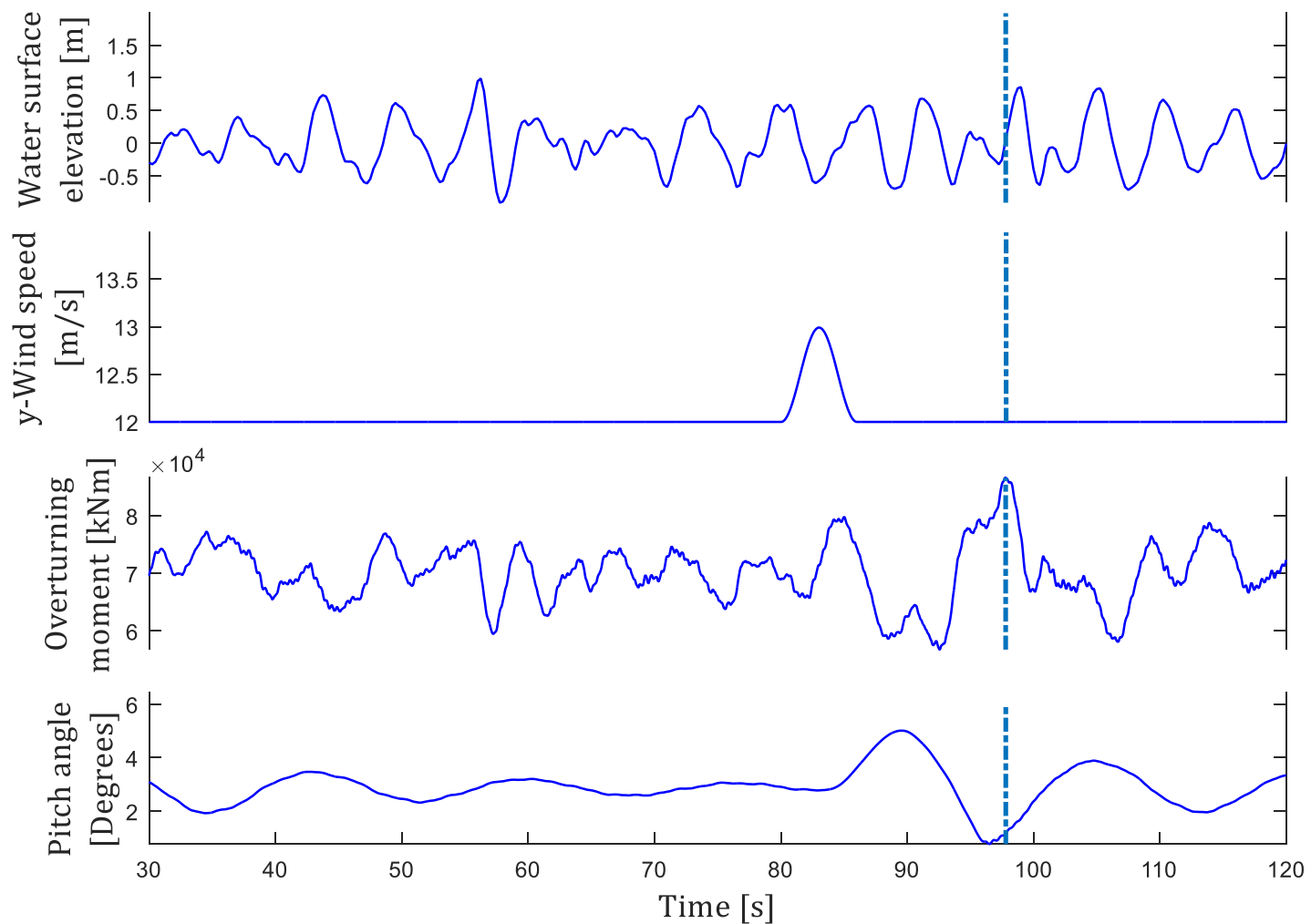

Figure 15 - Time-series of different parameters of the EWVS+ with wind speed of $12 \mathrm{~m} / \mathrm{s}$ 
Flapwise moment - EWSH-

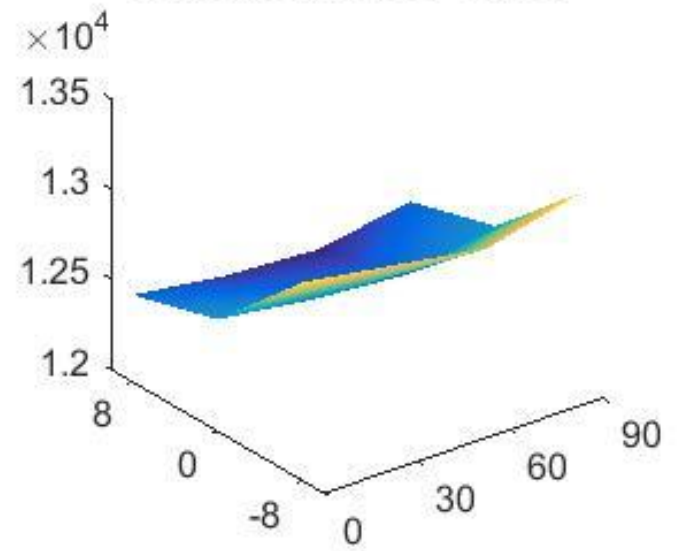

Edgewise moment - EWSH-

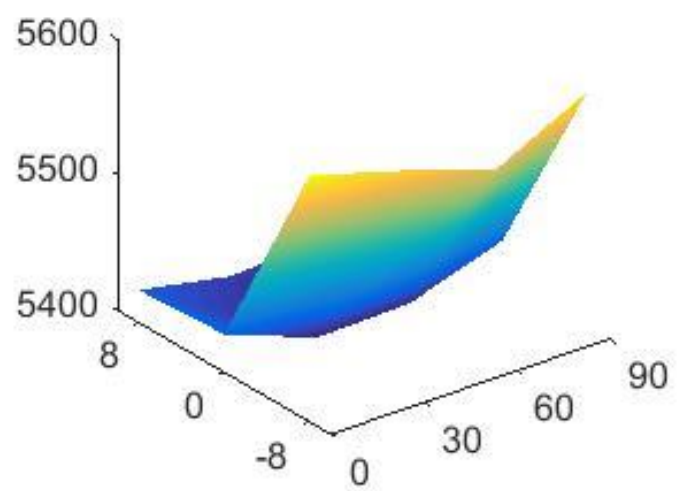

Figure 16 - Flapwise (left) and edgewise (right) moment caused by an EWSH- at a rated wind speed and the correlation with yaw angle $\left(0 \pm 8^{\circ}\right)$ and blade 1 initial azimuth angle $\left(0,30,60\right.$ and $\left.90^{\circ}\right)$
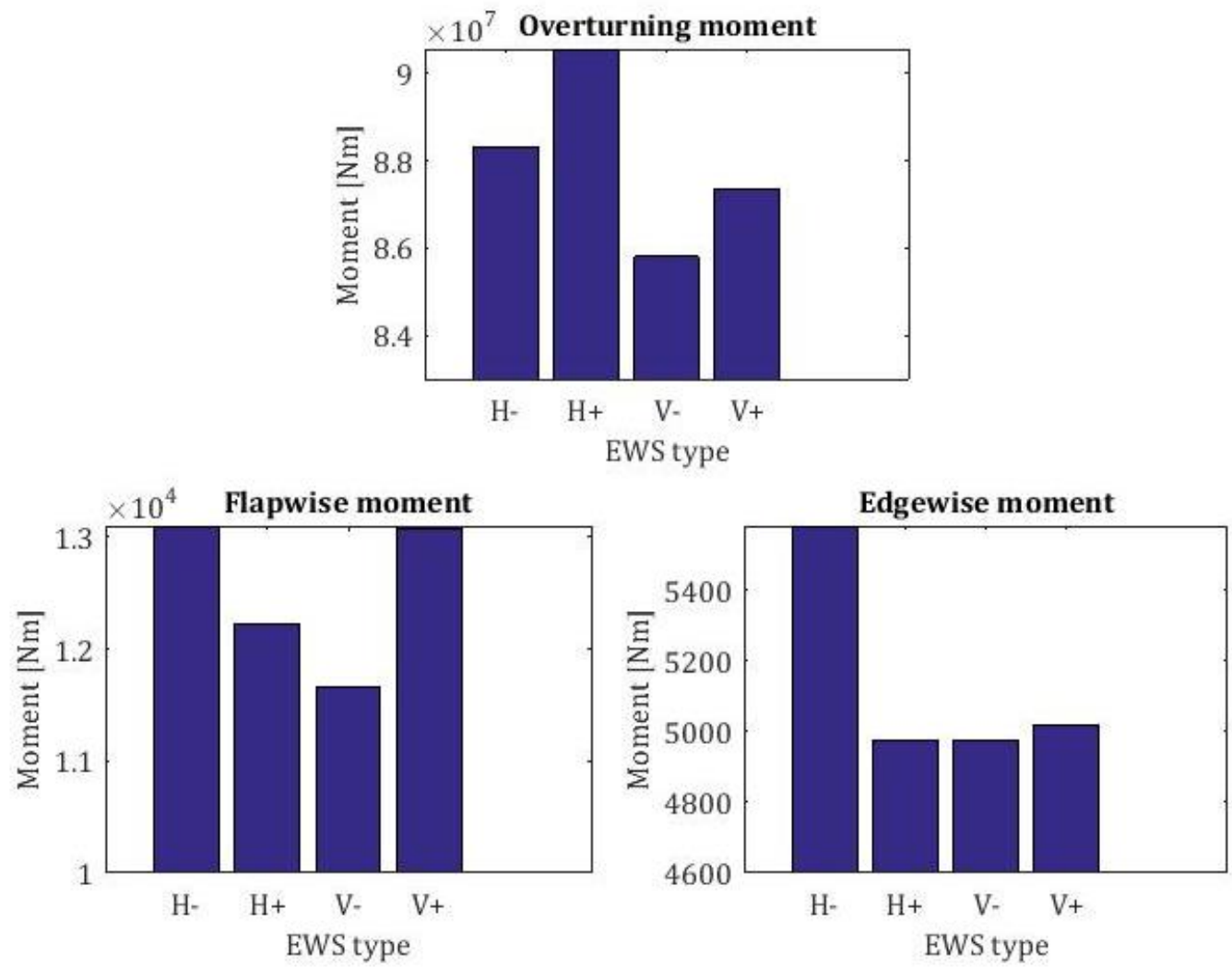

Figure 17 - Maximum values for Overturning, flapwise and edgewise moment for the 4 wind shears at a rated wind speed 

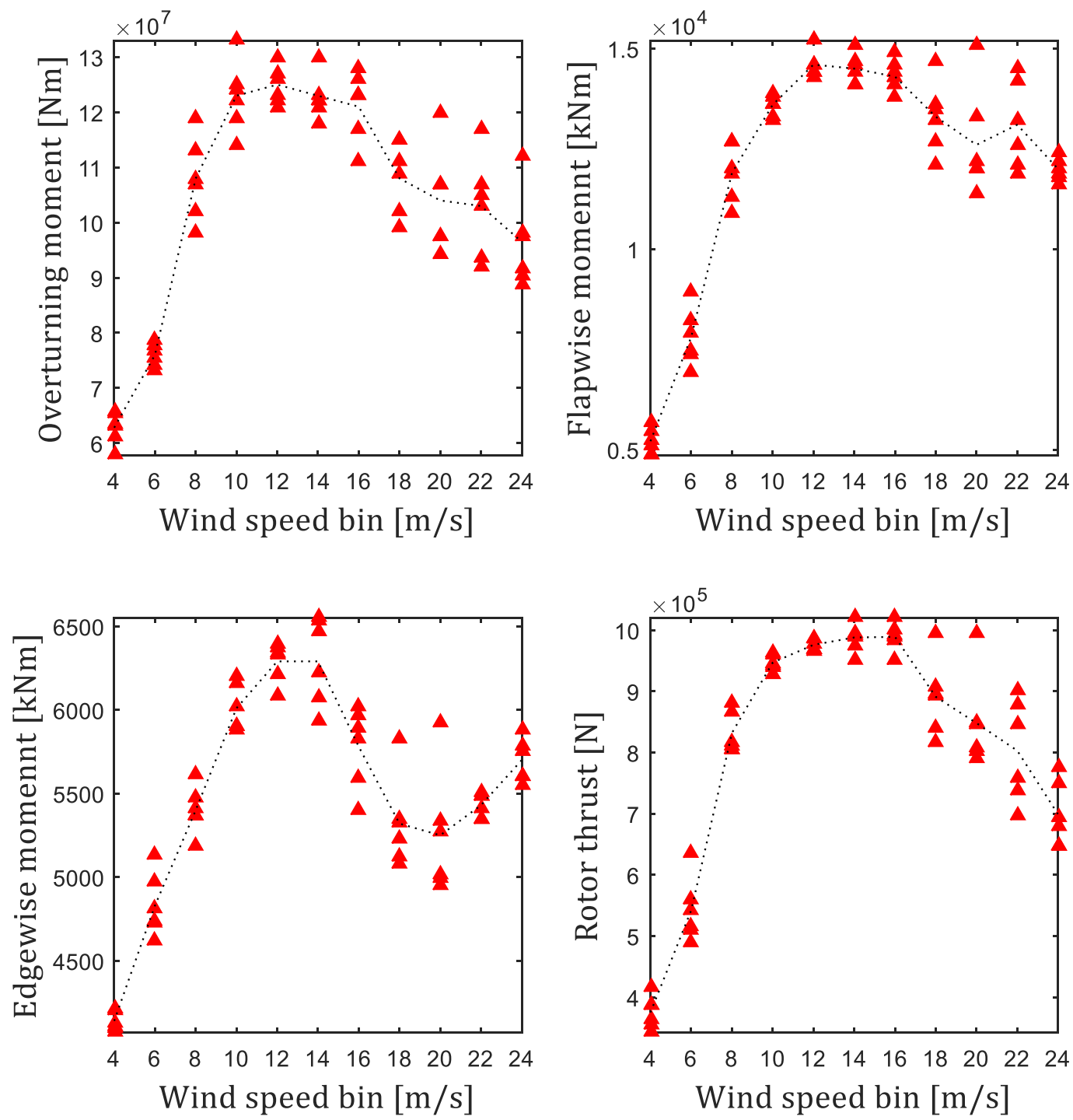

Figure 18 -Maximum values of the overturning, flapwise, edgewise moment and rotor thrust for each wind speed bin with $0^{\circ}$ yaw misalignment for DLC $1.6 a$

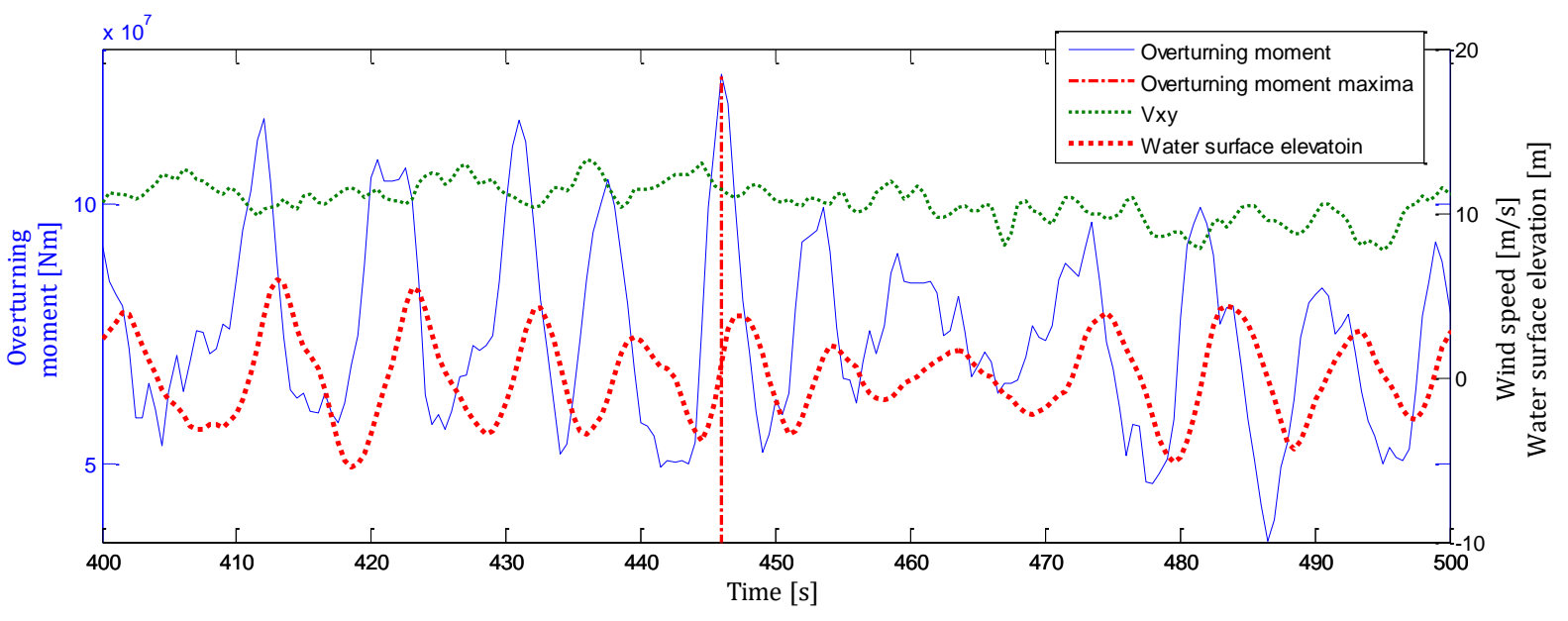

Figure 19 - Time-series of a random seed for $12 \mathrm{~m} / \mathrm{s}$ of DLC $1.6 a$. 

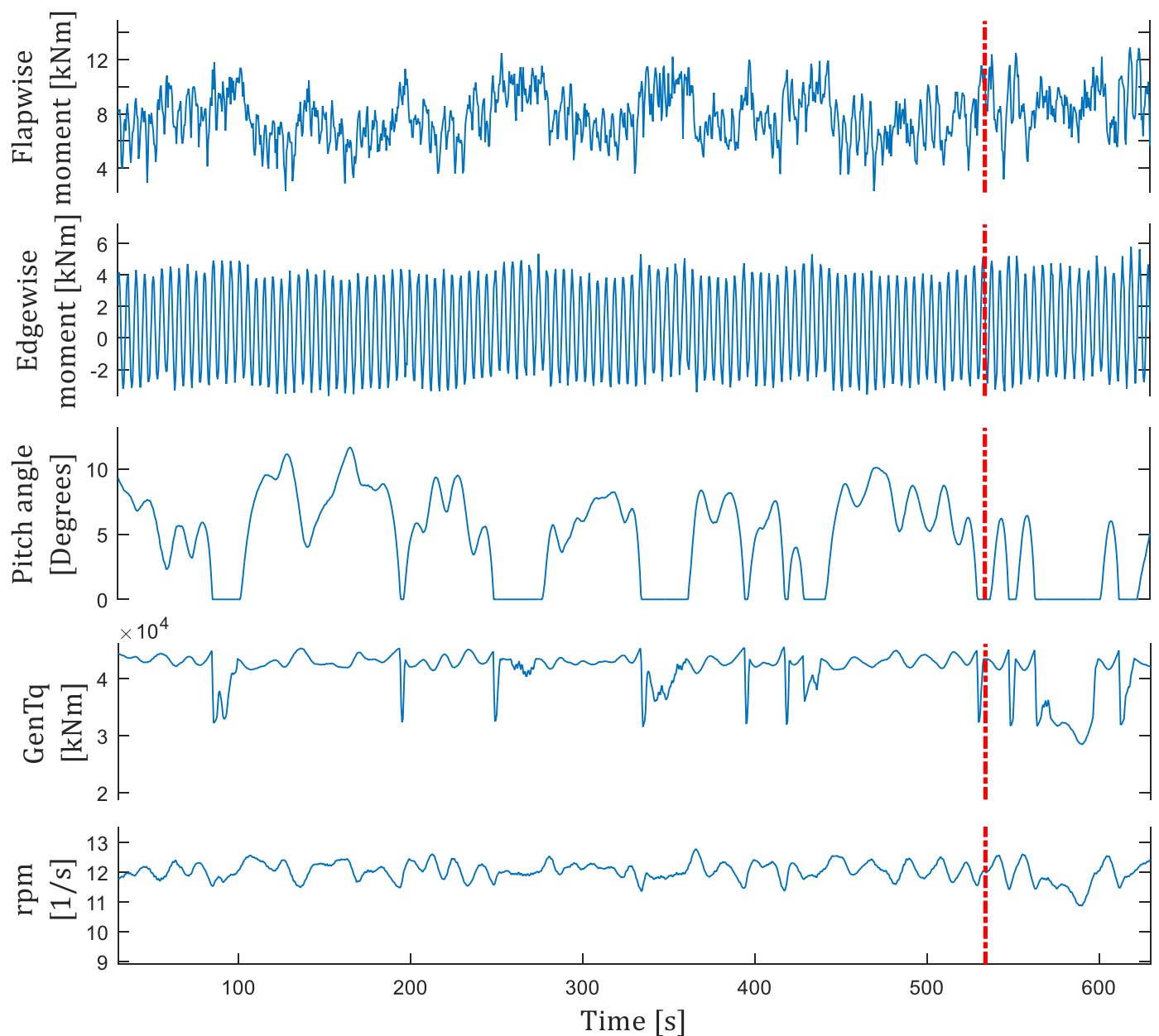

Figure 20 - Time-series for different variables of DLC 1.6a with a Vref $=12 \mathrm{~m} / \mathrm{s}$ for seed 5 

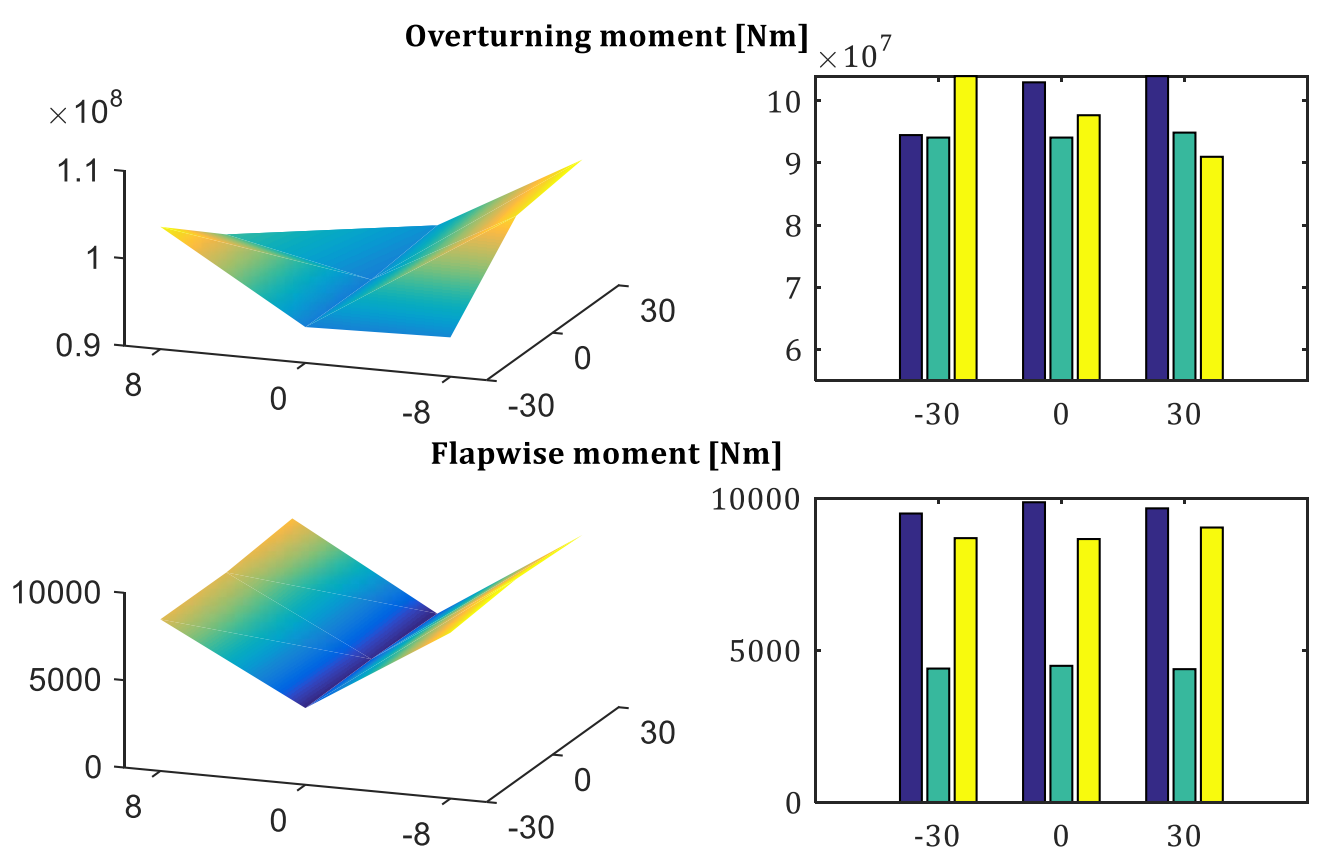

Edgewise moment $[\mathrm{Nm}]$

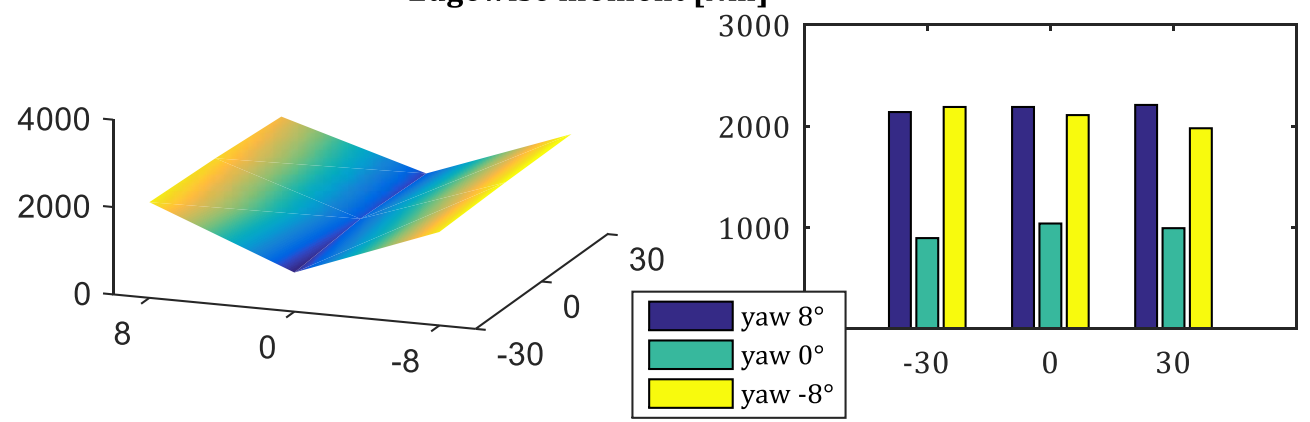

Figure 21 - Analysis of the correlation for DLC 6.1a between yaw angle, wind/wave misalignment and the three key-design parameters; overturning moment at the seabed level, the flapwise and edgewise moment at the root of the blade 


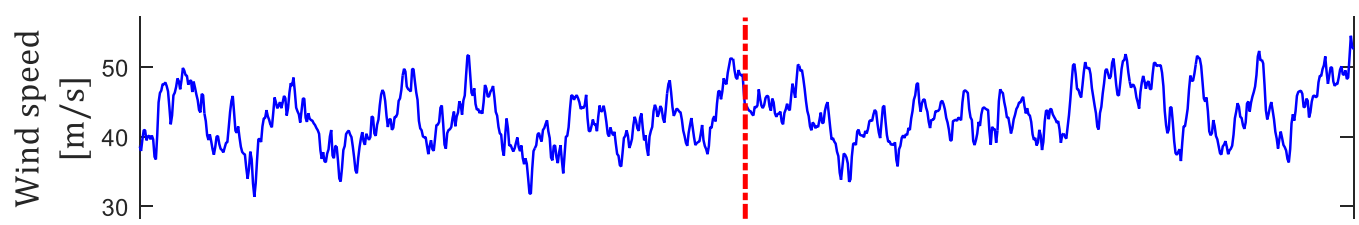

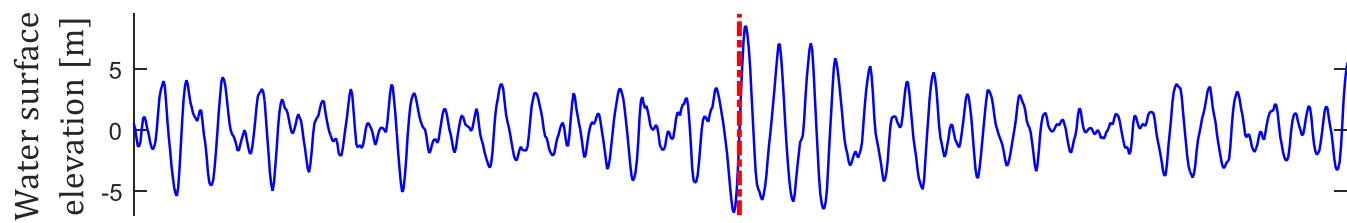

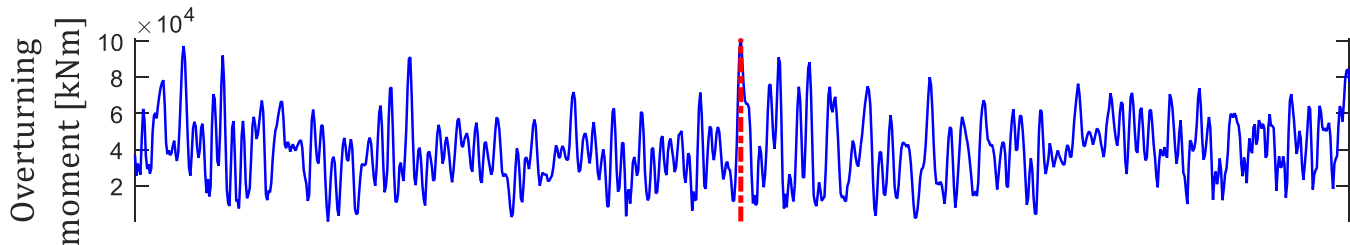

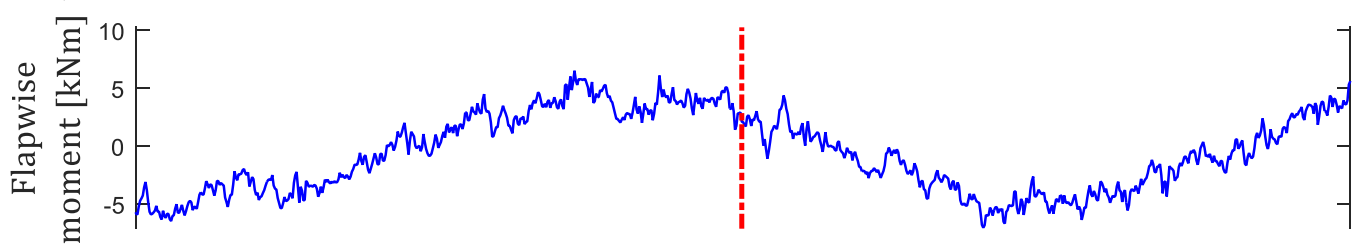

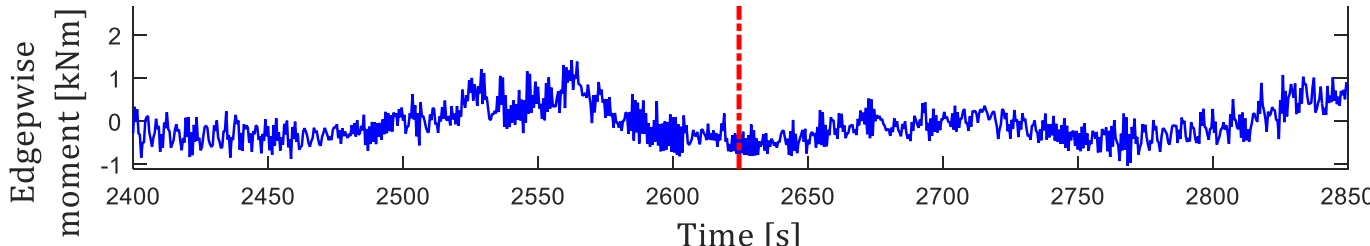

Figure 22 - Time-series of different output parameters from seed 2 of DLC 6.1a, yaw angle of $-8^{\circ}$ and $30^{\circ}$ of wind/wave misalignment 

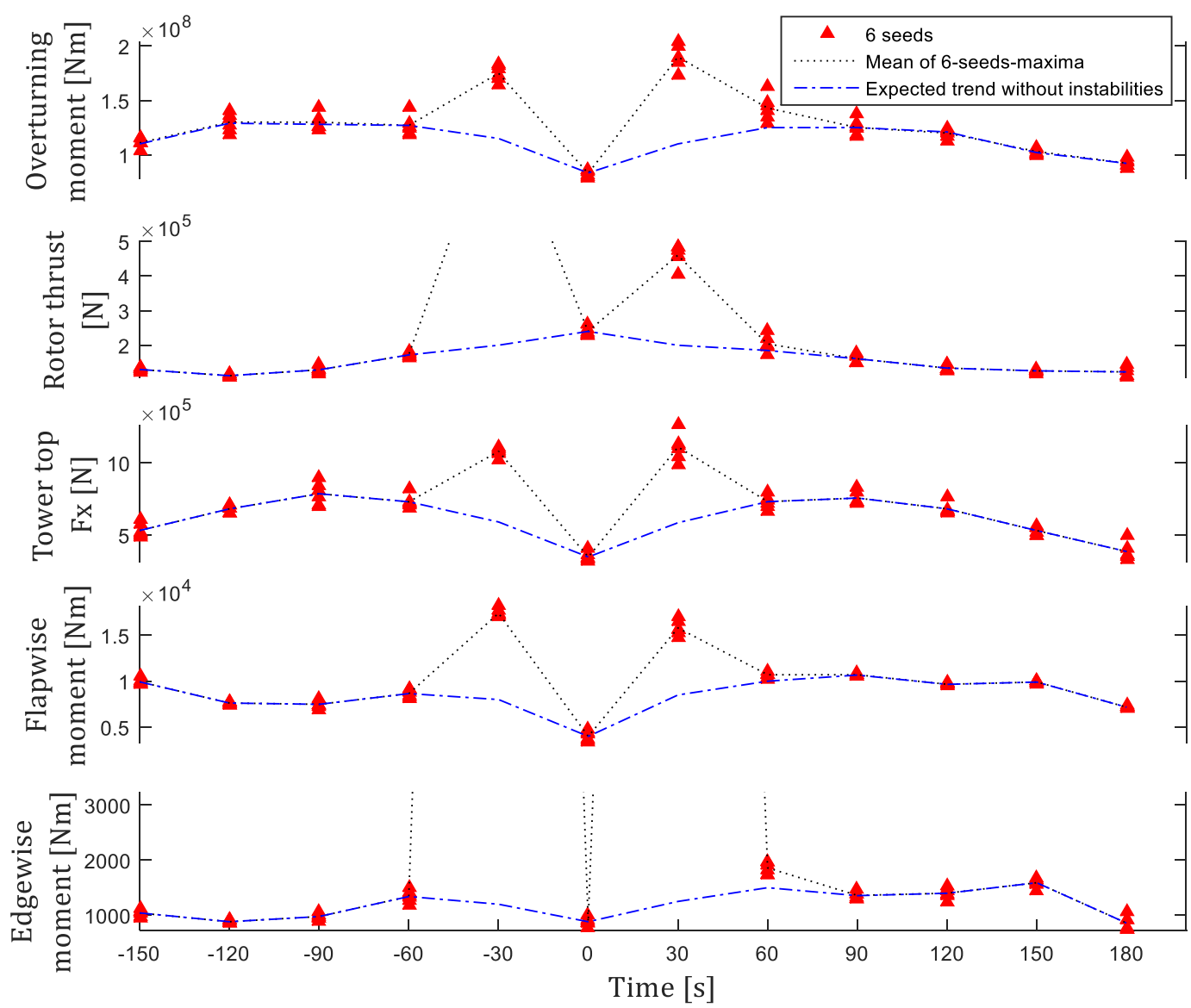

Figure 23 - Maximum and minimum values of all the seeds and mean of each yaw angle referring to the overturning moment at the seabed level ( $\mathrm{Nm}$ ) (top), rotor thrust (N) (middle) and shear force at the tower top (N) (lower)

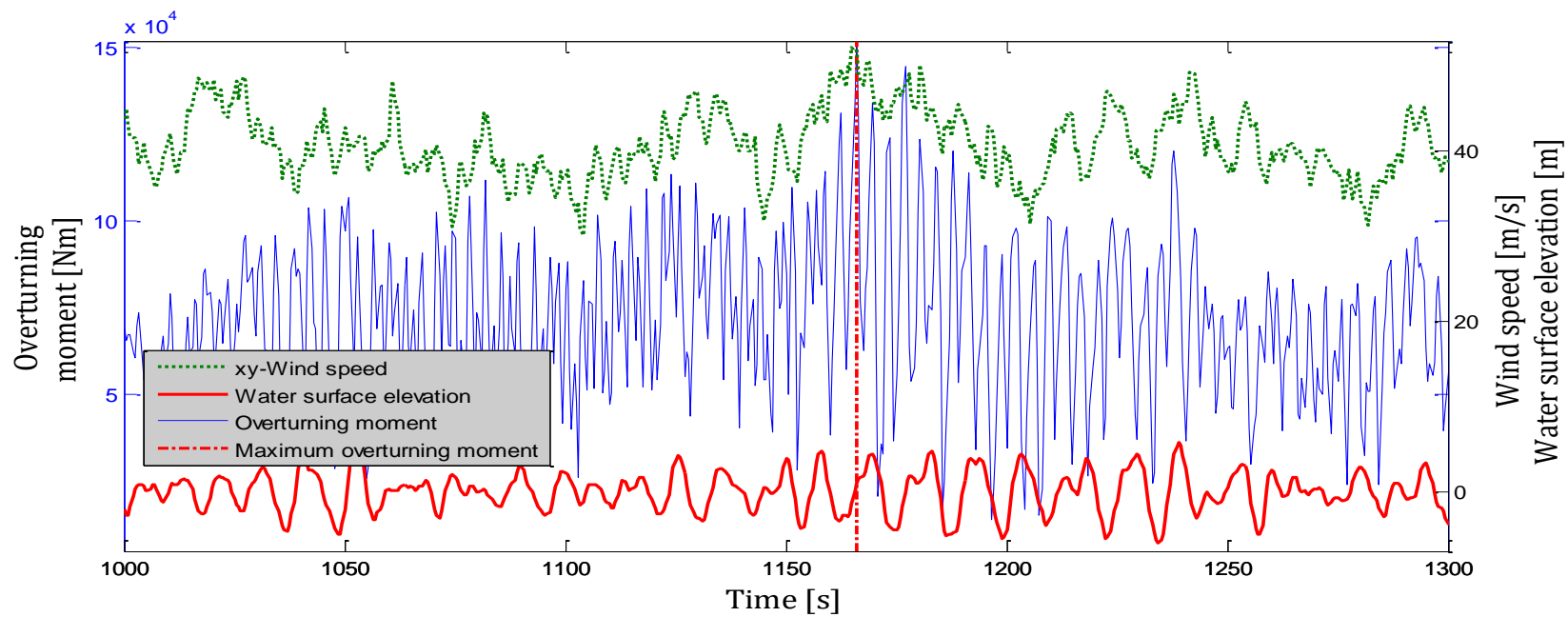

Figure 24 - Time-series of the overturning moment, wind speed and water surface elevation of a random seed representing the combination of $60^{\circ}$ of yaw angle and $30^{\circ}$ of wind/wave misalignment 


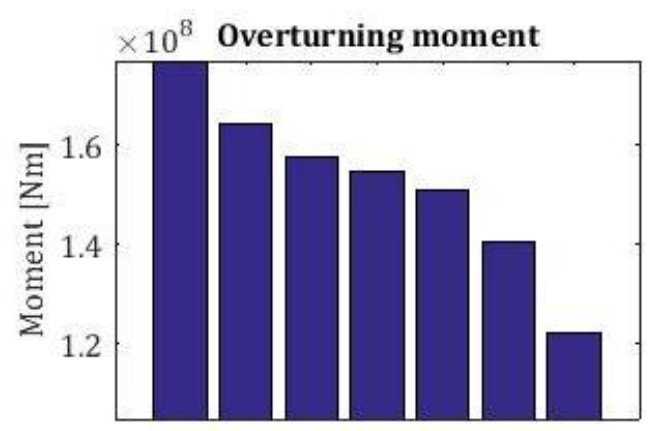

$\begin{array}{lllllllll}1.6 \mathrm{a} & 1.4 & 6.2 \mathrm{a} & 1.3 & 1.1 & 6.1 \mathrm{a} & 1.5\end{array}$

DLCs

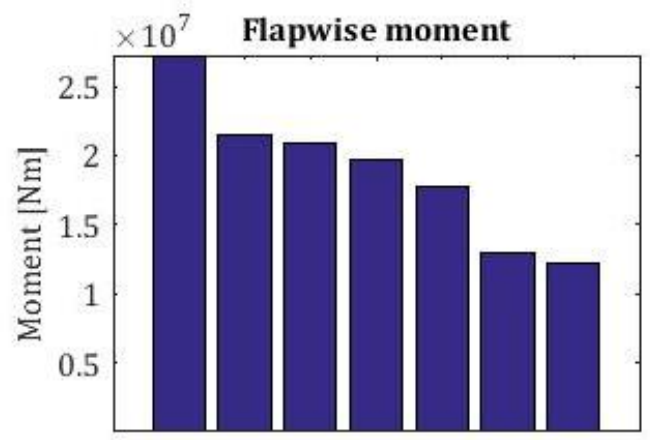

$\begin{array}{lllllll}1.4 & 1.1 & 1.3 & 1.6 \mathrm{a} & 1.5 & 6.1 \mathrm{a} 6.2 \mathrm{a}\end{array}$ DLCs

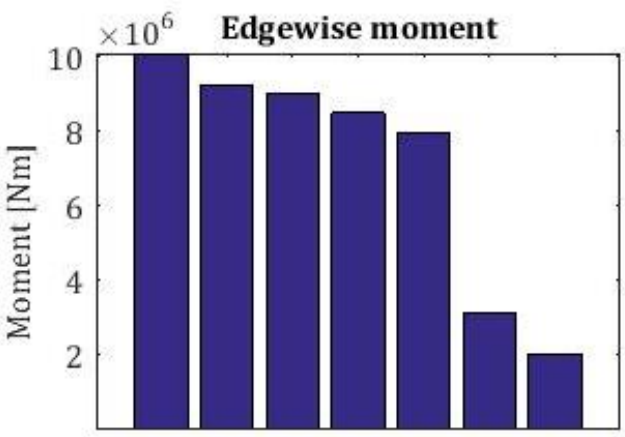

$\begin{array}{lllllll}1.4 & 1.1 & 1.3 & 1.6 \mathrm{a} & 1.5 & 6.1 \mathrm{a} 6.2 \mathrm{a}\end{array}$ DLCs

Figure 25 - Ranking of all DLCS for the overturning moment at the seabed level and flapwise and DLC edgewise moment at the root of the blade
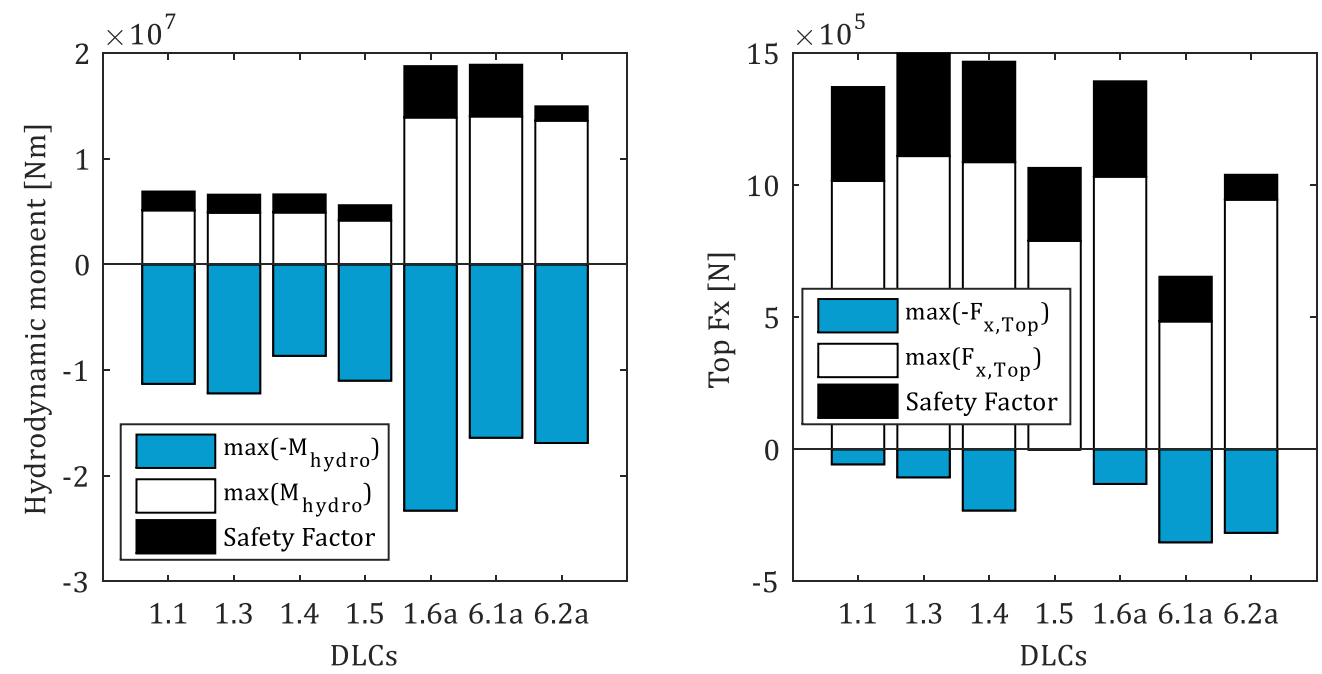

Figure 26 - Contribution of the hydrodynamic loading and tower top Fx 
Table 1 - General specifications of the 5MW monopile OWT [19]

\begin{tabular}{cc}
\hline \multicolumn{2}{c}{ Rotor/Nacelle assembly } \\
\hline Rated power & $5 \mathrm{MW}$ \\
$\begin{array}{c}\text { Number of blades/radius } \\
\text { Cut-in, Cut-out wind } \\
\text { speed }\end{array}$ & $3 / 63 \mathrm{~m}$ \\
Controllers & $3 \mathrm{~m} / \mathrm{s}, 25 \mathrm{~m} / \mathrm{s}$ \\
& \\
Rated rotor speed & Collective pitch control and generator \\
Support structure/foundation \\
\hline Structure & Monopile with rigid foundation \\
Hub height & $90 \mathrm{~m}$ above MSL \\
Water level & $20 \mathrm{~m}$ above seabed \\
\hline
\end{tabular}

Table 2 - Extreme wave heights and wind speed at the hub as a function of the return period

\begin{tabular}{ccccc}
\hline $\boldsymbol{T}_{\text {return }}[\mathrm{yr}]$ & $\boldsymbol{H}_{\boldsymbol{S}}[\mathrm{m}]$ & $\boldsymbol{T}_{\boldsymbol{P}}[\mathbf{s}]$ & $\boldsymbol{H}_{\boldsymbol{m a x}}[\mathbf{m}]$ & $\boldsymbol{V}_{\boldsymbol{h u b}}[\mathrm{m} / \mathbf{s}]$ \\
\hline 1 & 6.06 & 9.70 & 11.27 & 31.70 \\
50 & 8.07 & 11.3 & 15.64 & 42.04 \\
\hline
\end{tabular}

Table 3 - Wind-conditioned wave height and the corresponding spectral peak period

\begin{tabular}{ccc}
\hline $\boldsymbol{V}_{\boldsymbol{h u b}}[\mathrm{m} / \mathbf{s}]$ & $\boldsymbol{H}_{\boldsymbol{S}}[\mathrm{m}]$ & $\boldsymbol{T}_{\boldsymbol{P}}[\mathbf{s}]$ (mean) \\
\hline $\mathbf{4}$ & 1,10 & 5,88 \\
$\mathbf{6}$ & 1,18 & 5,76 \\
$\mathbf{8}$ & 1,31 & 5,67 \\
$\mathbf{1 0}$ & 1,48 & 5,74 \\
$\mathbf{1 2}$ & 1,70 & 5,88 \\
$\mathbf{1 4}$ & 1,91 & 6,07 \\
$\mathbf{1 6}$ & 2,19 & 6,37 \\
$\mathbf{1 8}$ & 2,47 & 6,71 \\
$\mathbf{2 0}$ & 2,76 & 6,99 \\
$\mathbf{2 2}$ & 3,09 & 7,40 \\
$\mathbf{2 4}$ & 3,42 & 7,80 \\
\hline
\end{tabular}

Table 4 - List of design load cases

\begin{tabular}{cccccc}
\hline \multirow{2}{*}{ DLC } & \multicolumn{2}{c}{ Wind } & \multicolumn{2}{c}{ Waves } & \multirow{2}{*}{ Control / Events } \\
\cline { 2 - 4 } & Model & Speed & Model & Height & \\
\hline 1.1 & NTM & $V_{\text {in }}<V_{\text {hub }}<V_{\text {out }}$ & NSS & $H_{S}=E\left[H_{S} \mid V\right]$ & \multirow{2}{*}{ Extrapolation of loads } \\
1.3 & ETM & $V_{\text {in }}<V_{\text {hub }}<V_{\text {out }}$ & NSS & $H_{S}=E\left[H_{S} \mid V\right]$ & \\
1.4 & ECD & $V_{\text {hub }}=V_{r} \pm 2 \frac{m}{S}, V_{r}$ & NSS & $H_{S}=E\left[H_{S} \mid V\right]$ & \\
1.5 & EWS & $V_{\text {in }}<V_{\text {hub }}<V_{\text {out }}$ & NSS & $H_{S}=E\left[H_{S} \mid V\right]$ & \\
$1.6 \mathrm{a}$ & NTM & $V_{\text {in }}<V_{\text {hub }}<V_{\text {out }}$ & SSS & $H_{S}=H_{S, S S S}$ & \\
$6.1 \mathrm{a}$ & EWM & $V_{\text {hub }}=0.95 \cdot V_{\text {ref }}$ & ESS & $H_{S}=1.09 \cdot H_{S, 50}$ & \\
$6.2 \mathrm{a}$ & EWM & $V_{\text {hub }}=0.95 \cdot V_{\text {ref }}$ & ESS & $H_{S}=1.09 \cdot H_{S, 50}$ & Loss of electrical network \\
$6.2 \mathrm{~b}$ & EWM & $\left.V_{\text {hub }}\right)=V_{\text {e } 50}$ & RWH & $H_{S}=H_{\text {red } 50}$ & Loss of electrical network \\
\hline
\end{tabular}


Table 5 - Comparison between the extrapolated values of DLC 1.1 and the results from DLC 1.3

\begin{tabular}{|c|c|c|c|}
\hline & $\begin{array}{l}\text { Overturning } \\
\text { moment } \\
(\mathbf{N} \cdot \mathbf{m})\end{array}$ & $\begin{array}{l}\text { Flapwise moment } \\
(\mathbf{N} \cdot \mathbf{m})\end{array}$ & $\begin{array}{l}\text { Edgewise } \\
\text { moment } \\
(\mathbf{N} \cdot \mathbf{m})\end{array}$ \\
\hline \multirow[t]{2}{*}{$\begin{array}{l}\text { Gumbel } \\
\text { prediction }\end{array}$} & $1.510 \mathrm{E}+08$ & $2.151 E+07$ & $9.235 E+06$ \\
\hline & $-2.37 \%$ & $+2.90 \%$ & $+2.66 \%$ \\
\hline DLC 1.3 & $1.547 E+08$ & $2.090 \mathrm{E}+07$ & $8.996 \mathrm{E}+06$ \\
\hline
\end{tabular}

Table 6 - Characteristic and design load of all the DLCs with the required partial safety factors.

\begin{tabular}{ccccccccc}
\hline & \multicolumn{3}{c}{ Characteristic load } & Safety Factor & \multicolumn{3}{c}{ Design load } \\
\hline DLC & $\begin{array}{c}\text { Overturning } \\
\text { moment } \\
(\mathrm{Nm})\end{array}$ & $\begin{array}{c}\text { Flapwise } \\
\text { moment } \\
(\mathrm{Nm})\end{array}$ & $\begin{array}{c}\text { Edgewise } \\
\text { moment } \\
(\mathrm{Nm})\end{array}$ & Type & value & $\begin{array}{c}\text { Overturning } \\
\text { moment } \\
(\mathrm{Nm})\end{array}$ & $\begin{array}{c}\text { Flapwise } \\
\text { moment } \\
(\mathrm{Nm})\end{array}$ & $\begin{array}{c}\text { Edgewise } \\
\text { moment } \\
(\mathrm{Nm})\end{array}$ \\
\hline 1.1 & $1.208 \mathrm{E}+08$ & $1.721 \mathrm{E}+07$ & $7.388 \mathrm{E}+07$ & Normal & 1.25 & $1.510 \mathrm{E}+08$ & $2.151 \mathrm{E}+07$ & $9.235 \mathrm{E}+06$ \\
1.3 & $1.146 \mathrm{E}+08$ & $1.548 \mathrm{E}+07$ & $6.664 \mathrm{E}+06$ & Normal & 1.35 & $1.547 \mathrm{E}+08$ & $2.090 \mathrm{E}+07$ & $8.996 \mathrm{E}+06$ \\
1.4 & $1.217 \mathrm{E}+08$ & $2.019 \mathrm{E}+07$ & $7.473 \mathrm{E}+06$ & Normal & 1.35 & $1.643 \mathrm{E}+08$ & $2.726 \mathrm{E}+07$ & $1.009 \mathrm{E}+07$ \\
1.5 & $9.056 \mathrm{E}+07$ & $1.310 \mathrm{E}+07$ & $5.890 \mathrm{E}+06$ & Normal & 1.35 & $1.223 \mathrm{E}+08$ & $1.769 \mathrm{E}+07$ & $7.952 \mathrm{E}+06$ \\
$1.6 \mathrm{a}$ & $1.310 \mathrm{E}+08$ & $1.461 \mathrm{E}+07$ & $6.294 \mathrm{E}+06$ & Normal & 1.35 & $1.769 \mathrm{E}+08$ & $1.972 \mathrm{E}+07$ & $8.497 \mathrm{E}+06$ \\
$6.1 \mathrm{a}$ & $9.114 \mathrm{E}+07$ & $9.631 \mathrm{E}+06$ & $2.339 \mathrm{E}+06$ & Normal & 1.35 & $1.230 \mathrm{E}+08$ & $1.300 \mathrm{E}+07$ & $3.158 \mathrm{E}+06$ \\
$6.2 \mathrm{a}$ & $1.164 \mathrm{E}+08$ & $1.107 \mathrm{E}+07$ & $2.238 \mathrm{E}+06$ & Abnormal & 1.10 & $1.281 \mathrm{E}+08$ & $1.218 \mathrm{E}+07$ & $2.462 \mathrm{E}+06$ \\
$6.2 \mathrm{~b}$ & $1.388 \mathrm{E}+08$ & $1.807 \mathrm{E}+07$ & $6.722 \mathrm{E}+06$ & Abnormal & 1.10 & $1.526 \mathrm{E}+08$ & $1.988 \mathrm{E}+07$ & $7.394 \mathrm{E}+06$ \\
\hline
\end{tabular}

